\title{
Oxidation, Thermal, and Storage Stability Studies of Jatropha Curcas Biodiesel
}

\author{
Siddharth Jain and M. P. Sharma \\ Biofuel Research Laboratory, Alternate Hydro Energy Centre, Indian Institute of Technology Roorkee, \\ Roorkee, Uttarakhand 247667, India \\ Correspondence should be addressed to Siddharth Jain, arth_jain2001@yahoo.co.in
}

Received 19 August 2011; Accepted 29 September 2011

Academic Editors: K. Kaygusuz and Y. Y. Lee

Copyright ( $\odot 2012$ S. Jain and M. P. Sharma. This is an open access article distributed under the Creative Commons Attribution License, which permits unrestricted use, distribution, and reproduction in any medium, provided the original work is properly cited.

\begin{abstract}
The present work reports the results of the study of the effect of metal contaminants on the oxidation, thermal, and storage stability of Jatropha curcas biodiesel (JCB) with and without antioxidants. Taking Pyrogallol (PY) as the most effective antioxidant based on the earlier work of the authors, JCB was mixed with different transition metals- $\mathrm{Fe}, \mathrm{Ni}, \mathrm{Mn}, \mathrm{Co}$, and $\mathrm{Cu}$ in different concentrations. Induction period (IP) was measured using Rancimat method (EN 14112). The ASTM D6468 and thermogravimetric analysis (TGA) methods are used for evaluating the thermal behavior of JCB. Based on results, several correlations are developed for assessing the oxidation, thermal, and storage stability. For the purpose of optimization, response surface methodology (RSM) is used. A comparison between the experimental values and those predicted by the correlation shows that all the data points lie within $\pm 10 \%$ deviation lines of the experimental results. The optimized concentration of PY for 2 ppm metal-contaminated biodiesel to have an IP of $6 \mathrm{hr}$ is 326.96, 361.64, 386.15, 417.24, and $600 \mathrm{ppm}$ for Fe, Ni, Mn, Co, and Cu, respectively. From the experiments it is found that if metal concentration is 0 , then, $200 \mathrm{ppm}$ of PY is sufficient to make biodiesel stable for 6 months. If metal $(\mathrm{Fe})$ concentration is $2 \mathrm{ppm}$ or more, then $800 \mathrm{ppm} \mathrm{PY}$ is sufficient to make biodiesel stable for 5.5 months. This is the first study of its kind being reported in the literature in which RSM is used for design of experiment for developing the correlation for oxidation, thermal, and storage stability. The models developed by RSM will be highly useful for predicting the optimum antioxidant concentration to impart maximum fuel stability in JCB.
\end{abstract}

\section{Introduction}

Stability of biodiesel may be affected by its interaction with contaminants, light, temperature, factors causing sediments formation, changes in color, and other changes that reduce the cleanliness of the fuel [1]. Biodiesel produced from vegetable oils and other feed stocks have been found to be more susceptible to oxidation owing to the exposure to oxygen of the air and higher temperature, mainly, due to the presence of varying numbers of double bonds in the free fatty acid molecules. The chemical reactivity of fatty oils and their esters is, therefore, divided into oxidative and thermal instability that can be determined by the amount and configuration of the olefinic unsaturation in the fatty acid chains. Most of the plant-derived fatty oils like soybean and rapeseed contain poly-unsaturated fatty acids that are methylene interrupted rather than conjugated. This structural feature is key to understanding both oxidative and thermal instability.

Different vegetable oils obtained from soybean, castor, sunflower, cotton, corn, palm, and so forth are widely used for biodiesel production in different parts of the world depending on the cultivation of oil crops. India imports about $40-50 \%$ of total domestic edible oil demand, and therefore, it is impossible to divert these resources for biodiesel production [2]. Therefore, attention has been focused to the use of nonedible oil resources like Jatropha, pongamia, neem, and so forth for biodiesel production in the country. Jatropha curcas plantations are under cultivation on more than 40000 ha of land under the National Biofuel Program of the Government of India [2]. The oil from the seeds of the Jatropha curcas plant would become the source of biodiesel 
TABLE 1: Physicochemical properties of JCB as per different standards.

\begin{tabular}{lcccccc}
\hline S. no. & Property (unit) & ASTM D6751 & ASTM D6751 limits & IS 15607 & IS 15607 limits & JCB \\
\hline 1 & Flash point $\left({ }^{\circ} \mathrm{C}\right)$ & D-93 & Min. 130 & IS 1448 & & 172 \\
2 & Viscosity at $40{ }^{\circ} \mathrm{C}(\mathrm{cSt})$ & D-445 & $1.9-6.0$ & IS 1448 & & 4.38 \\
3 & Water and sediment (vol\%) & D-2709 & Max. 0.05 & D-2709 & Max. 0.05 & 0.05 \\
4 & Free glycerin (\% mass) & D-6584 & Max. 0.02 & D-6584 & Max. 0.02 & 0.01 \\
5 & Total glycerin (\% mass) & D-6584 & Max. 0.24 & D-6584 & Max. 0.24 & 0.03 \\
6 & Oxidation stability of FAME, hrs & EN14112 & 3 & EN 14112 & Min. 6 & 3.27 \\
7 & Oxidation stability of FAME blend, hrs & - & - & EN 590 & Min. 20 & - \\
8 & Free glycerol & D6584 & $0.02(\max )$ & D6584 & $0.02(\max )$ & 0.01 \\
9 & Total glycerol & D6584 & $0.25(\max )$ & D6584 & $0.25(\max )$ & 0.12 \\
10 & Acid value & D664 & $0.5(\max )$ & D664 & $0.5(\max )$ & 0.38 \\
11 & Ester content & - & - & EN14103 & $96.5(\max )$ & 98.5 \\
\hline
\end{tabular}

which will be used as substitute of diesel fuel on a significant scale in India [2].

The influence of antioxidants on the oxidation stability of biodiesel was studied by Mittelbach and Schober [3] who showed that the oxidation stability is influenced by the addition of different natural and synthetic antioxidants. Dunn [4] examined the effectiveness of five antioxidants, namely, tert-butylhydroquinone (TBHQ), butylated hydroxyanisole (BHA), butylated hydroxytoluene (BHT), propyl gallate (PrG), and R-tocopherol in mixtures with soybean oil fatty acid methyl esters (SMEs) and found that increasing the antioxidant concentration increases the activity thereby leading to the improved oxidation stability.

Sarin et al. [5] have improved the oxidation stability of Jatropha biodiesel by mixing the palm biodiesel in different proportions. The effect of natural and synthetic antioxidants on the oxidative stability of palm biodiesel was examined by Liang et al. [6] who found that crude palm oil methyl ester (CPOME) containing $600 \mathrm{ppm}$ of vitamin $\mathrm{E}$ was found to exhibit oxidative stability of more than $6 \mathrm{~h}$ as per the specifications of the European standard for biodiesel (EN 14214). Sarin et al. [7] have further evaluated the influence of metal contaminants on the oxidation stability of Jatropha biodiesel and found that the metals had a detrimental effect on the oxidation stability. Even small concentrations of metal contaminants showed nearly the same effect on the oxidation stability as large concentrations. $\mathrm{Cu}$ has been found to have the strongest detrimental and catalytic effect.

The effect of antioxidants on refined palm oil was examined by Fritsch et al. [8] who found that TBHQ has a better effect as an antioxidant on refined palm oil compared to BHT and BHA. Although numerous papers are available on the effect of antioxidants storage, thermal and oxidation stability of biodiesel, and the influence of the presence of metal on the oxidation and thermal behaviors of biodiesel synthesized from edible oils, little work is reported on the oxidation and thermal stability of biodiesel from nonedible oil resources. Accordingly, it was felt strongly to develop correlations which will be helpful for determination of the amount of antioxidants actually required to be added to stabilize the biodiesel.

The present paper reports the results of the study carried out by alternate hydroenergy centre (AHEC) on the influence of antioxidants and metals on the oxidation, thermal, and storage stabilities of JCB. For this purpose different transition metals like $\mathrm{Fe}, \mathrm{Ni}, \mathrm{Mn}, \mathrm{Co}$, and $\mathrm{Cu}$ commonly found in the alloys and metallurgy used in the manufacturing of storage tanks and barrels were blended in JCB with varying concentrations $(\mathrm{mg} / \mathrm{L})$ in JCB. The effectiveness of different antioxidants has already been reported in our earlier paper, in which PY was found to be the most effective antioxidant, and therefore, only PY is used as antioxidant in the present study [9]. Based on the results obtained, different correlations are developed for the oxidation, thermal, and storage stability as a function of antioxidants and metal contaminants. The amount of antioxidants was also optimized to get the specifications of oxidation, thermal, and storage stability of JCB. Depending upon various correlations developed a correlation between the oxidation and thermal stability has also been developed and reported in this paper.

\section{Material and Methods}

All chemicals including PY were of analytical grade (AR) and purchased from Sigma Aldrich, India. Different transition metals, $\mathrm{Fe}, \mathrm{Ni}, \mathrm{Mn}, \mathrm{Co}$, and $\mathrm{Cu}$, were also purchased from Sigma Aldrich, India. Biodiesel was prepared using two-step acid-base-catalyzed transesterification processes developed by the authors and reported in our previous publications [10, 11]. Physicochemical properties and fatty acid composition of JCB are shown in Tables 1 and 2, respectively. Biodiesel was mixed with predetermined concentrations of different metal contaminants and PY and these biodiesel samples were subjected to various tests to measure the oxidation, thermal, and storage stability. ASTM D6468 and TGA methods were used for the measurement of thermal stability in terms of insoluble formation (Ins) and activation energy $\left(E_{a}\right)$, respectively, $[12,13]$ and Rancimat method was used for the measurement of IP of biodiesel [14].

Table 1 shows that most of the properties of JCB are satisfying the ASTM D6751 and IS 15607. Oxidation stability of JCB is satisfying the ASTM D6751 but at the same time it is less than required by IS 15607 . The reason of low oxidation stability of JCB is because of high amount of unsaturated fatty acids as shown in Table 2. 
TABle 2: Fatty acid composition of JCB.

\begin{tabular}{lc}
\hline Fatty acid & \% Composition \\
\hline Palmitic acid (P) & 16.8 \\
Stearic acid (S) & 7.7 \\
Oleic acid (O) & 39.1 \\
Linoleic acid (L) & 36.0 \\
Linolenic acid (LL) & 0.2
\end{tabular}

2.1. Range of Parameters. Different concentrations of antioxidants varying from 100 to $600 \mathrm{ppm}$ were added to JCB to check the effectiveness of antioxidants. Based on the result as will be discussed in the next section, PY was found as the most effective antioxidant to increase the oxidation stability of JCB and therefore only PY has been chosen and mixed in different concentrations in JCB to study its effect on oxidation, storage, and thermal stability of JCB. Different metal contaminants with concentration varying from 0.5 to $3 \mathrm{ppm}$ were also added to JCB and it is observed that if metal concentration is increased to more than $2 \mathrm{ppm}$, the effect of metal concentration on oxidation stability becomes constant and accordingly a maximum concentration of $2 \mathrm{ppm}$ has been taken for different metals to be added in JCB. Table 3 gives the range of parameters in terms of $\mathrm{PY}$ concentration and metal contaminants used for measuring the different type of stabilities.

Samples were prepared using the previous range of parameters for the present study. Two kinds of approaches, namely, simple statistical approach using Sigma plot and RSM approach, were used to develop the correlation between different stabilities with antioxidants and metal concentration. RSM has been used to optimize the antioxidants and metal concentration for optimum oxidation, thermal, and storage stability.

2.2. Design of Experiment Using RSM. A 5-level-2-factor central composite design (CCD) including 2 replicates at factorial, 2 replicates at axial, and 5 replicates at the centre point leading to 21 runs was used for fitting the response surface for oxidation and thermal stability. Metal contaminants and antioxidant concentration were the independent variables selected to be optimized for obtaining the $6 \mathrm{hrs}$ IP of JCB. The coded and uncoded levels of the independent variables are given in Table 4 .

A 5-level-3-factor central composite design (CCD) including 2 replicates at factorial, 2 replicates at axial, and 6 replicates at the centre point leading to 34 runs was used for fitting the response surface for storage stability. Metal contaminants, antioxidant concentration, and storage time were the independent variables selected to be optimized for obtaining the $6 \mathrm{hrs}$ IP of JCB. The coded and uncoded levels of the independent variables are given in Table 5.

The experimental data obtained using the previous procedures were analyzed by the response surface regression procedure using the following second-order polynomial equation:

$$
y=\beta_{0}+\sum \beta_{i} x_{i}+\sum \beta_{i i} x_{i}^{2}+\sum \beta_{i j} x_{i} x_{j},
$$

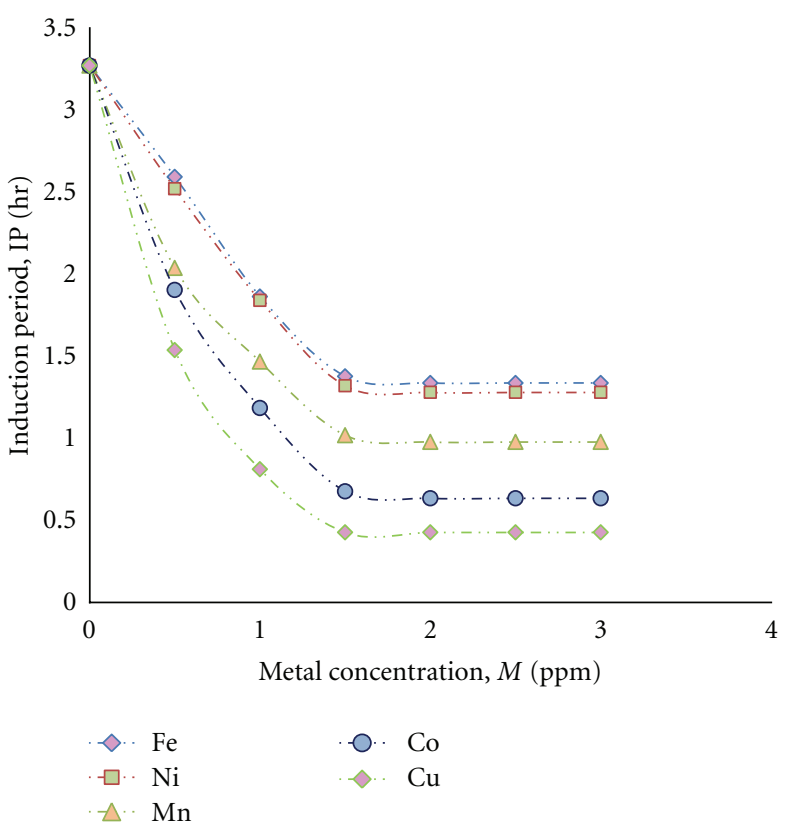

FIGURE 1: Effect of metal contamination on oxidation stability of JCB.

where $y$ is the response (IP/Ins/ $\left.E_{a}\right), x_{i}$ and $x_{j}$ are the uncoded independent variables, and $\beta_{0}, \beta_{i}, \beta_{i i}$, and $\beta_{i j}$ are intercept, linear, quadratic, and interaction constant coefficients, respectively. Design Expert software package 6.0 was used for regression analysis and analysis of variance (ANOVA). Several optimization points for each independent variable at an IP of 6 hrs were obtained. Confirmatory experiments were carried out to validate the equations using the combinations of independent variables which were not part of the original experimental design but were within the experimental region.

JCB has also been blended with petroleum diesel to see the effect of blending of JCB with diesel on its oxidation stability. For this purpose, different blends were prepared and added with different antioxidants as well as metal contaminants. The range of parameters used for the experiments is given in Table 6.

\section{Results and Discussion}

\subsection{Oxidation Stability of JCB}

3.1.1. Effect of Metal Contamination on Oxidation Stability of JCB. As reported earlier, different transition metals, $\mathrm{Fe}, \mathrm{Ni}$, $\mathrm{Mn}, \mathrm{Co}$, and $\mathrm{Cu}$, commonly found in metal containers were blended with varying concentrations (ppm) in JCB samples. Figure 1 shows that the presence of these metals depressed the oxidation stability of biodiesel. The presence of metals in biodiesel resulted in acceleration of free radical oxidation due to a metal-mediated initiation reaction. Copper had strongest catalytic effect and other metals, iron, nickel, manganese, and cobalt also had strong negative influence on oxidation stability. Figure 1 shows that IP became almost constant as 
TABLE 3: Range of parameters for the stability study of JCB.

\begin{tabular}{lccc}
\hline S. no. & Type of stability & Parameters & Concentration range \\
\hline 1 & Oxidation stability & Antioxidant concentration, $A$ & 100 to 600 ppm \\
& Metal concentration, $M$ & 0.5 to 2 ppm \\
\hline 2 & Thermal stability & Antioxidant concentration, $A$ & 100 to 600 ppm \\
& & Metal concentration, $M$ & 0.5 to 2 ppm \\
\hline & & Antioxidant concentration, $A$ & 100 to 800 ppm \\
3 & Storage stability & Metal concentration, $M$ & 0.5 to 2 ppm \\
& & Storage time & 0 to 6 months \\
\hline
\end{tabular}

TABLE 4: Independent variable and levels used for CCD in oxidation and thermal process for all the metals.

\begin{tabular}{lcccccc}
\hline Variables & \multirow{2}{*}{ Symbols } & \multicolumn{3}{c}{ Levels } & & 0 \\
& & $-1.68179(-\alpha)$ & -1 & +1 & $+1.68179(+\alpha)$ \\
\hline Antioxidants concentration $(\mathrm{ppm})$ & $A$ & 0 & 150 & 300 & 450 & 600 \\
Metal contaminants concentration $(\mathrm{mg} / \mathrm{L})$ & $M$ & 0 & 0.5 & 1 & 1.5 & 2 \\
\hline
\end{tabular}

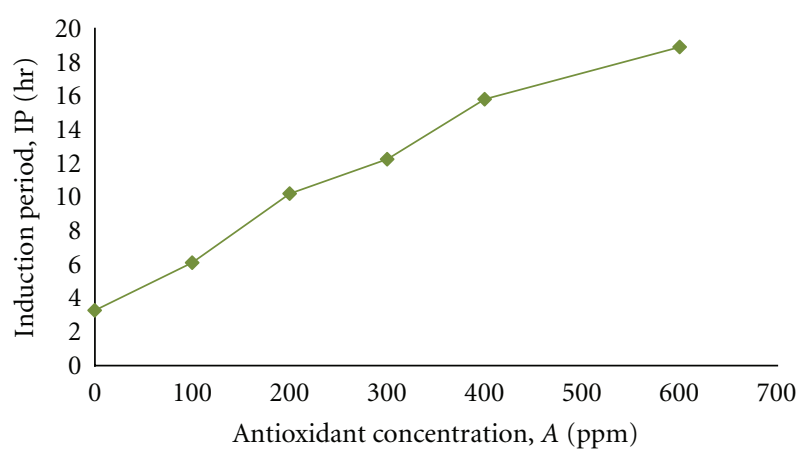

Figure 2: Effect of PY on oxidation stability of JCB.

concentration of metal is increased. This proves that the influence of metals was catalytic, as even small concentrations of metals had nearly the same effect on oxidation stability as large amounts.

3.1.2. Effect of PY on Oxidation Stability of JCB. Figure 2 shows the effect of PY on the oxidation stability of JCB. The PY concentration varied from 0 to $600 \mathrm{ppm}$. From the figure it is clear that as the amount of antioxidant increased in the JCB, the IP also get increased from $3.27 \mathrm{hrs}$ to $18 \mathrm{hrs}$. From the figure it is clear that $100 \mathrm{ppm}$ PY is sufficient to make biodiesel oxidatively stable, if it does not contain any metal contaminants.

\subsection{Storage Stability of JCB}

3.2.1. Effect of Metal Contamination on Storage Stability of $J C B$. Figure 3 shows the effect of metal contaminants on various properties of JCB. The AV of fresh JCB without metal contaminants is $0.15 \mathrm{mg} \mathrm{KOH} / \mathrm{gm}$ which increases to $0.45 \mathrm{mg} \mathrm{KOH} / \mathrm{gm}$ over a period of 6 months. PV of fresh JCB without metal contaminants is $4.16 \mathrm{mg} / \mathrm{kg}$ which increases to $38.26 \mathrm{mg} / \mathrm{kg}$ after 6 months due to oxidation of unsaturated fatty acid compounds [1]. The viscosity of fresh
JCB without metal contaminants is found as $4.38 \mathrm{cSt}$ which increases to $5.63 \mathrm{cSt}$ over a period of 6 months. When metal contaminants were added in JCB, then the rate of increases of viscosity became higher due to acceleration in the oxidation process which in turn increases the peroxide formation [1, 7]. Due to the previous reasons the stability of metal-contaminated JCB deteriorates drastically. Fe has the least effect on the storage stability while $\mathrm{Cu}$ has the strongest effect on storage stability of JCB. This is in agreement with Sarin et al. [7] who investigated the effect of metal contaminants on the oxidation stability in terms of IP of biodiesel and found that Fe has the least effect and $\mathrm{Cu}$ has the strongest effect on oxidation stability.

Figure 4 shows relative variation in unsaturated fatty acids amount. For fresh JCB the percentages of oleic, linoleic, and linolenic acid are the same for all the samples with and without metal contaminants. As the time passes, the relative percentages of oleic, linoleic, and linolenic acid of JCB without metal contaminants vary from 39.1 to $47.37 \%, 36$ to $20.99 \%$, and 0.2 to $0.026 \%$, respectively. However, when metals are mixed with JCB, then relative percentage of oleic acid after 6 months is 47.48, 47.67, 47.78, and 47.87\% for $\mathrm{Fe}, \mathrm{Ni}, \mathrm{Mn}, \mathrm{Co}$, and $\mathrm{Cu}$, respectively (Figure 4(a)). The percentage of linoleic acid after 6 months is 20.78, 20.35, 20.13, 19.92, and 19.70 for $\mathrm{Fe}, \mathrm{Ni}, \mathrm{Mn}, \mathrm{Co}$, and $\mathrm{Cu}$, respectively (Figure 4(b)). The percentage of linolenic acid after 6 months is $0.024,0.22,0.021,0.019$, and 0.018 for $\mathrm{Fe}, \mathrm{Ni}, \mathrm{Mn}$, $\mathrm{Co}$, and $\mathrm{Cu}$, respectively (Figure $4(\mathrm{c})$ ). These findings reveal that an increase in relative percentage of oleic acid however decreases in relative percentage of linoleic and linolenic acid representing the acceleration in oxidation process after the addition of metal contaminants. This also shows that as the oxidation deterioration advances, linolenic and linoleic acids methyl decreases and fraction of oleic acid methyl becomes relatively high. These finding is also in agreement with the work of Yamane et al. [15].

3.2.2. Effect of Antioxidants on Storage Stability of JCB. The effect of antioxidant on various properties of JCB is given 
TABLE 5: Independent variable and levels used for CCD in oxidation process with respect to time for all the metals.

\begin{tabular}{|c|c|c|c|c|c|c|}
\hline \multirow{2}{*}{ Variables } & \multirow{2}{*}{ Symbols } & \multicolumn{5}{|c|}{ Levels } \\
\hline & & $-1.68179(-\alpha)$ & -1 & 0 & +1 & $+1.68179(+\alpha)$ \\
\hline Antioxidants concentration (ppm) & $A$ & 0 & 150 & 300 & 450 & 600 \\
\hline Metal contaminants concentration (ppm) & $M$ & 0 & 0.5 & 1 & 1.5 & 2 \\
\hline Storage time (months) & $T$ & 0 & 1.5 & 3 & 4.5 & 6 \\
\hline
\end{tabular}

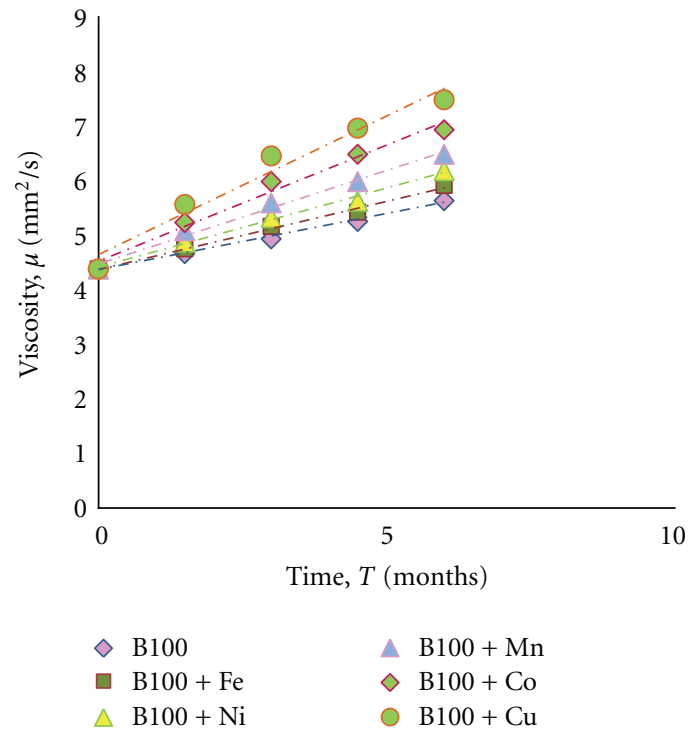

(a)

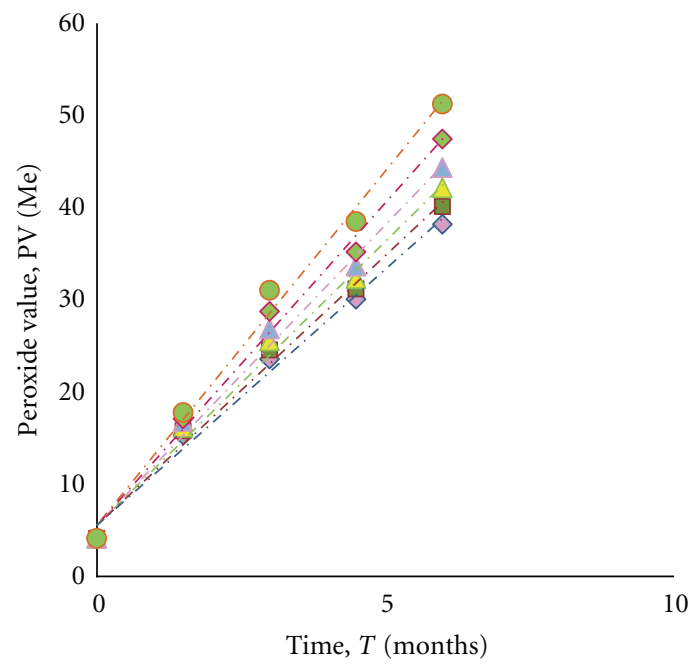

(c)

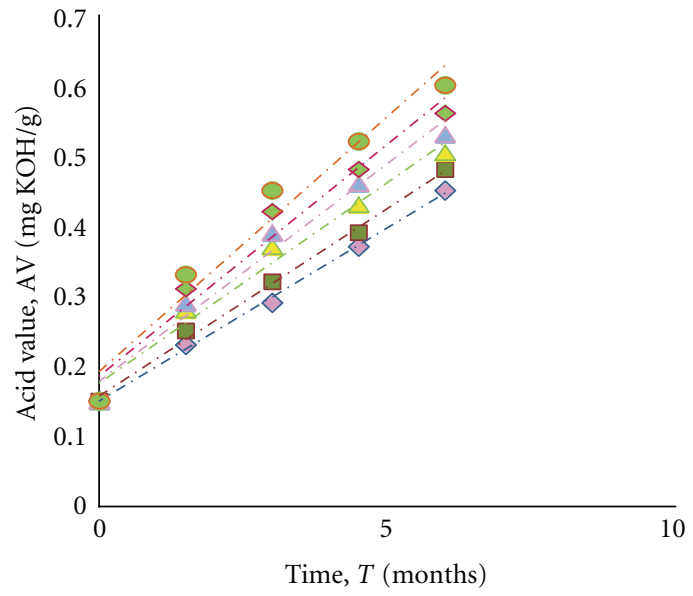
$\diamond \mathrm{B} 100$
- $\mathrm{B} 100+\mathrm{Fe}$
$\triangle \mathrm{B} 100+\mathrm{Mn}$
$\mathrm{B} 100+\mathrm{Ni}$
$\diamond \mathrm{B} 100+\mathrm{Co}$
$\mathrm{B} 100+\mathrm{Cu}$

(b)

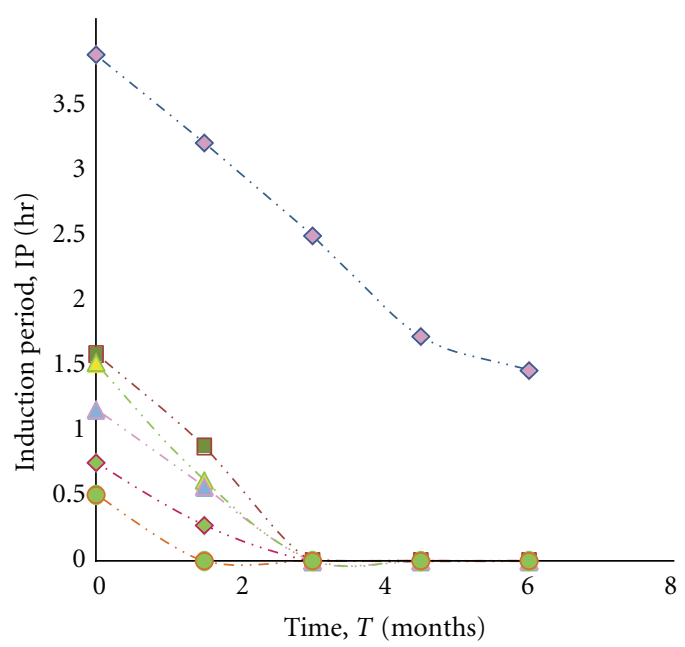

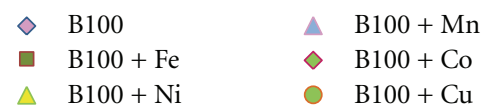

(d)

FIGURE 3: Effect of metal contamination on storage stability of JCB.

in Figure 5 which shows that after the addition of antioxidant, the rate of increase in AV with respect to time decreases due to deacceleration in the oxidation process. The peroxide formation is found to decrease by addition of antioxidants in JCB compared to JCB without antioxidants. This is in agreement with the Das et al. [16] who found that peroxide formation decreases with increase in antioxidant concentration, thereby leading to the lower rate of increase of viscosity that became lower. A number of reports confirm that the retardation of oxidation process became higher as 

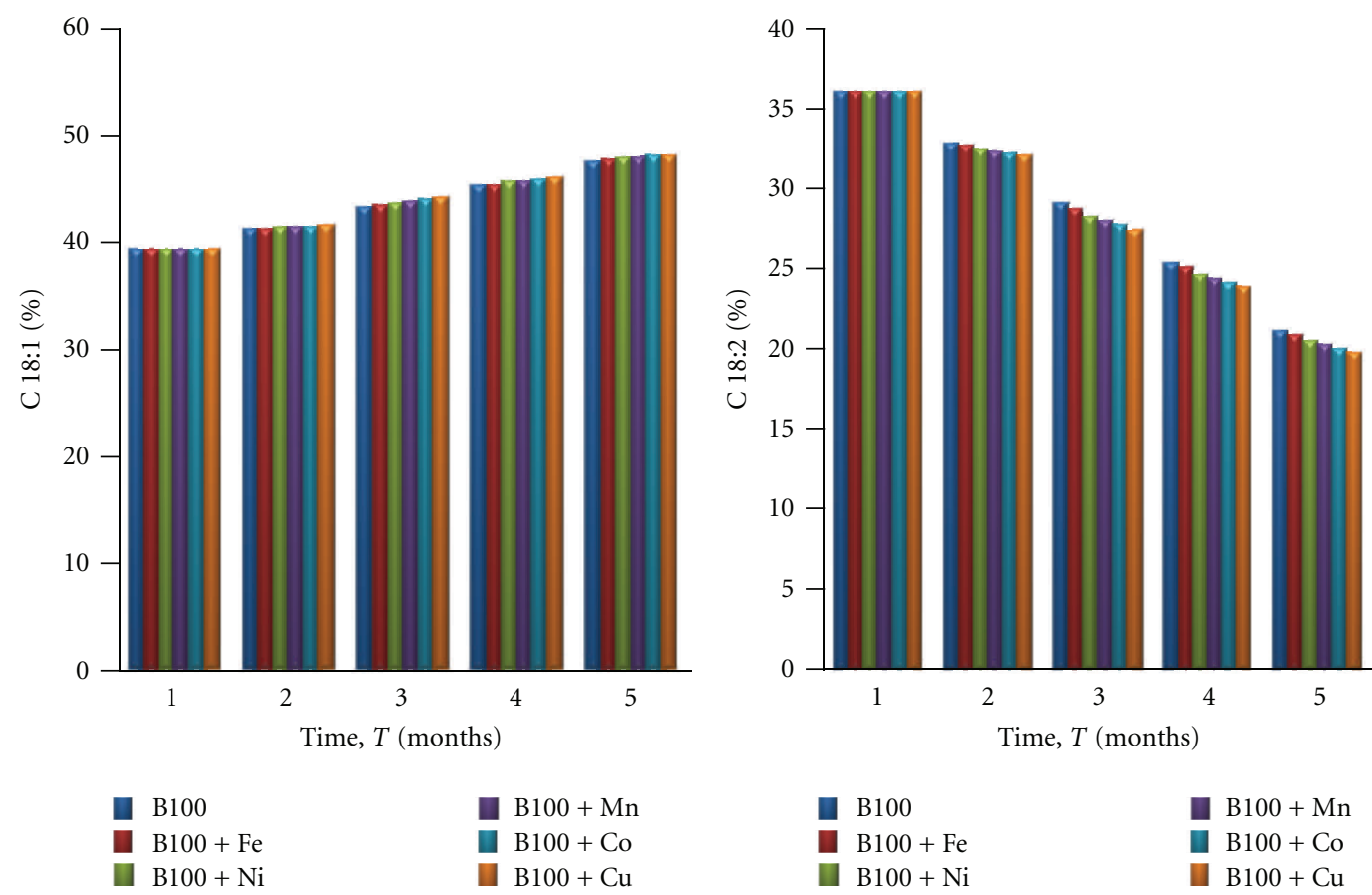

(a)

(b)

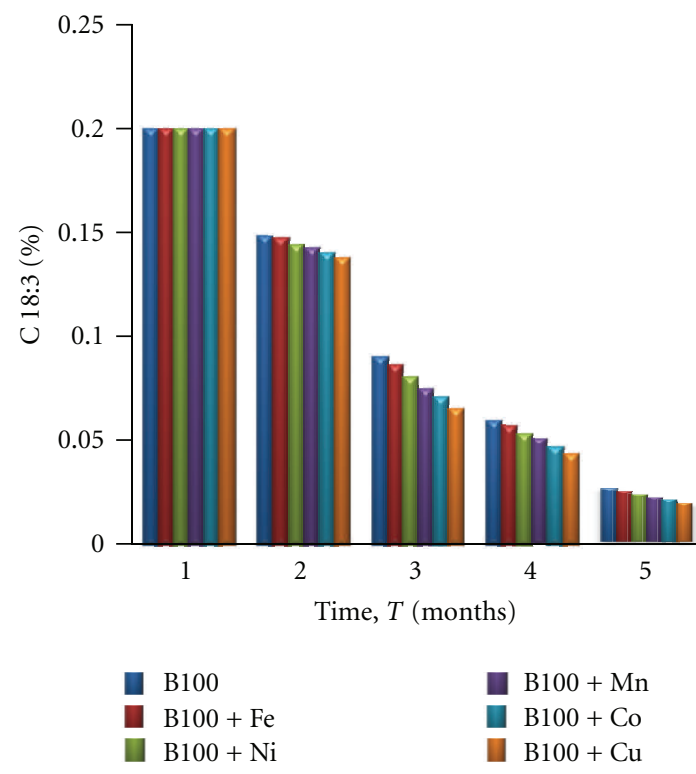

(c)

FIGURE 4: Effect of metal contaminants on unsaturated fatty acids with respect to time.

TABLE 6: Range of parameters for the oxidation stability study of JCB/petrodiesel blends.

\begin{tabular}{lcc}
\hline S. no. & Parameters & Range \\
\hline 1 & Antioxidant concentration, $A$ & 50 to $300 \mathrm{ppm}$ \\
2 & Metal concentration, $M$ & 0.5 to $2 \mathrm{ppm}$ \\
\hline
\end{tabular}

the antioxidant concentration is increased [7, 16-21]. The reduced rate of peroxide formation led to the increase in long-term storage stability in terms of IP which indicates that it is possible to store biodiesel for longer period of time by adding the antioxidant. These observations are explained by the fact that PY (chain breaking antioxidant) contained a highly labile hydrogen which can be more easily abstracted by a peroxy radical than fatty oil or ester hydrogen. The resulting antioxidant free radical was either stable or further reacted to form a stable molecule which was further resistant to chain oxidation process. Thus the chain breaking antioxidants help to interrupt the oxidation chain reaction in order to enhance 
TABLE 7: Correlation developed for oxidation stability for different metal contaminants.

\begin{tabular}{lccc}
\hline S. no. & Metal & Correlations & $\begin{array}{c}\text { Regression } \\
\text { coefficient }\end{array}$ \\
\hline 1 & Fe & IP $=0.1255(A)^{0.7334}(M)^{-0.472}$ & 0.93 \\
2 & Ni & IP $=0.11735(A)^{0.7279}(M)^{-0.4663}$ & 0.92 \\
3 & Mn & IP $=0.0932(A)^{0.7578}(M)^{-0.477}$ & 0.95 \\
4 & Co & IP $=0.0841(A)^{0.7648}(M)^{-0.5871}$ & 0.95 \\
5 & Cu & IP $=0.063(A)^{0.7986}(M)^{-0.7599}$ & 0.94 \\
\hline
\end{tabular}

TABLE 8: Correlation developed for thermal stability for different metal contaminants.

\begin{tabular}{lccc}
\hline S. no. & Metal & Correlations & $\begin{array}{c}\text { Regression } \\
\text { coefficient }\end{array}$ \\
\hline \multirow{2}{*}{1} & \multirow{2}{*}{$\mathrm{Fe}$} & Ins $=2.975(M)^{0.1817}(A)^{-0.3156}$ & 0.92 \\
& & $E_{a}=8.23(M)^{-0.2239}(A)^{0.3279}$ & 0.92 \\
\hline \multirow{2}{*}{2} & \multirow{2}{*}{$\mathrm{Ni}$} & $\mathrm{Ins}=3.534(M)^{0.2122}(A)^{-0.3277}$ & 0.93 \\
& & $E_{a}=2.975(M)^{-0.3313}(A)^{0.4840}$ & 0.85 \\
\hline \multirow{2}{*}{3} & \multirow{2}{*}{$\mathrm{Mn}$} & Ins $=3.586(M)^{0.2124}(A)^{-0.3237}$ & 0.92 \\
& & $E_{a}=2.022(M)^{-0.3796}(A)^{0.5419}$ & 0.85 \\
\hline \multirow{2}{*}{4} & \multirow{2}{*}{$\mathrm{Co}$} & Ins $=3.751(M)^{0.2418}(A)^{-0.3164}$ & 0.95 \\
& & $E_{a}=0.499(M)^{-0.5474}(A)^{0.7625}$ & 0.77 \\
\hline \multirow{2}{*}{5} & \multirow{2}{*}{$\mathrm{Cu}$} & $\mathrm{Ins}=4.976(M)^{0.2003}(A)^{-0.3511}$ & 0.90 \\
& & $E_{a}=0.0395(M)^{-0.8432}(A)^{1.1645}$ & 0.74 \\
\hline
\end{tabular}

TABle 9: Correlation developed for storage stability for different metal contaminants.

\begin{tabular}{lccc}
\hline S. no. & Metal & Correlations & $\begin{array}{c}\text { Regression } \\
\text { coefficient }\end{array}$ \\
\hline 1 & $\mathrm{Fe}$ & $\mathrm{IP}=0.042(T)^{-0.2683}(A)^{0.9112}(M)^{-0.4654}$ & 0.93 \\
2 & $\mathrm{Ni}$ & $\mathrm{IP}=0.0406(T)^{-0.3314}(A)^{0.908}(M)^{-0.566}$ & 0.91 \\
3 & $\mathrm{Mn}$ & $\mathrm{IP}=0.0323(T)^{-0.3085}(A)^{0.9364}(M)^{-0.6322}$ & 0.92 \\
4 & $\mathrm{Co}$ & $\mathrm{IP}=0.0358(T)^{-0.302}(A)^{0.9151}(M)^{-0.6563}$ & 0.92 \\
5 & $\mathrm{Cu}$ & $\mathrm{IP}=0.0374(T)^{-0.2648}(A)^{0.8838}(M)^{-0.8805}$ & 0.91 \\
\hline
\end{tabular}

the stability [1]. The results were in agreement with the literature findings [16-21].

When antioxidants are mixed with $\mathrm{JCB}$, the oxidation process is retarded resulting in the decrease in relative percentage of oleic acid as shown in Figure 6(a) and increase in relative percentage of linoleic and linolenic acid indicating the retardation of oxidation process after the addition of PY (Figures 6(a), 6(b), and 6(c)).

\subsection{Thermal Stability of JCB}

3.3.1. Effect of Metal Contamination on Thermal Stability of $J C B$. To determine the effect of metal contaminants on thermal stability, the experiments were conducted by mixing the JCB with different metal contaminants-iron, nickel, manganese, cobalt, and copper in predetermined concentrations. Each experiment was repeated twice and the average value was considered for further calculation. Figure 7 shows that, for all of the metal contaminants, Ins values increase with the amount of metal contaminants because of accelerated oxidation of JCB in the presence of metal contaminants. The presence of these metals also reduces the $E_{a}$. The reason for this is the same because of the acceleration of free-radical oxidation as a result of a metalmediated initiation reaction, which in turn increases the polymer formation as well.

Figure 7 shows that $E_{a}$ and Ins became almost constant as concentration of metal is increased. This proves that the influence of metals was catalytic, as even small concentrations of metals had nearly the same effect on thermal stability as large amounts.

3.3.2. Effect of Antioxidants on Thermal Stability of JCB. Figure 8 shows that as the amount of PY increases, the $E_{a}$ and Ins formed was decreased because of retardation in the oxidation process.

\section{Development of Correlation}

The results of the effect of antioxidant and metal concentration indicated that these parameters play critical role in oxidation and thermal degradation of biodiesel. The correlations may be useful for biodiesel producers to know the amount of antioxidant required to be added to maintain the oxidation stability of metal contaminated biodiesel conforming to international standard. Several correlations were developed for oxidation, thermal, and storage stability as a function of metal contaminants, antioxidant concentration, and storage time which are given in Tables 7, 8, and 9.

\section{Optimization of Oxidation, Thermal, and Storage Stability}

\subsection{Optimization of Oxidation Stability}

5.1.1. Response Analysis of Fe-Contaminated Biodiesel. The application of RSM yields the following regression equations which are empirical relationship for thermal and oxidation stability in terms of antioxidant concentration and metal concentration:

$$
\begin{aligned}
\mathrm{IP}= & 3.52+0.030528 * A-1.84833 * M-5.66667 \\
& * 10^{-3} * A * M-7.19444 * 10^{-6} * A^{2}+0.16750 \\
& * M^{2} .
\end{aligned}
$$

The results from the two-factor factorial experiment in Table 10 are analyzed using Design-Expert software package. Common statistical tools in the analysis of variance table such as $F$ value and $P$ value are used to define the most important factors affecting the JCB oxidation stability. The $F$ value is defined as the ratio of the respective mean square effect and the mean square error. The $P$ value is defined as the smallest level of significance leading to rejection of the null hypothesis. It may be noted that the standard level of significance used to justify a claim of a statistically significant effect is 0.05 .

Equation (2) is plotted in Figures 9 and 10 as contour and response surface plots of oxidation stability in terms of 

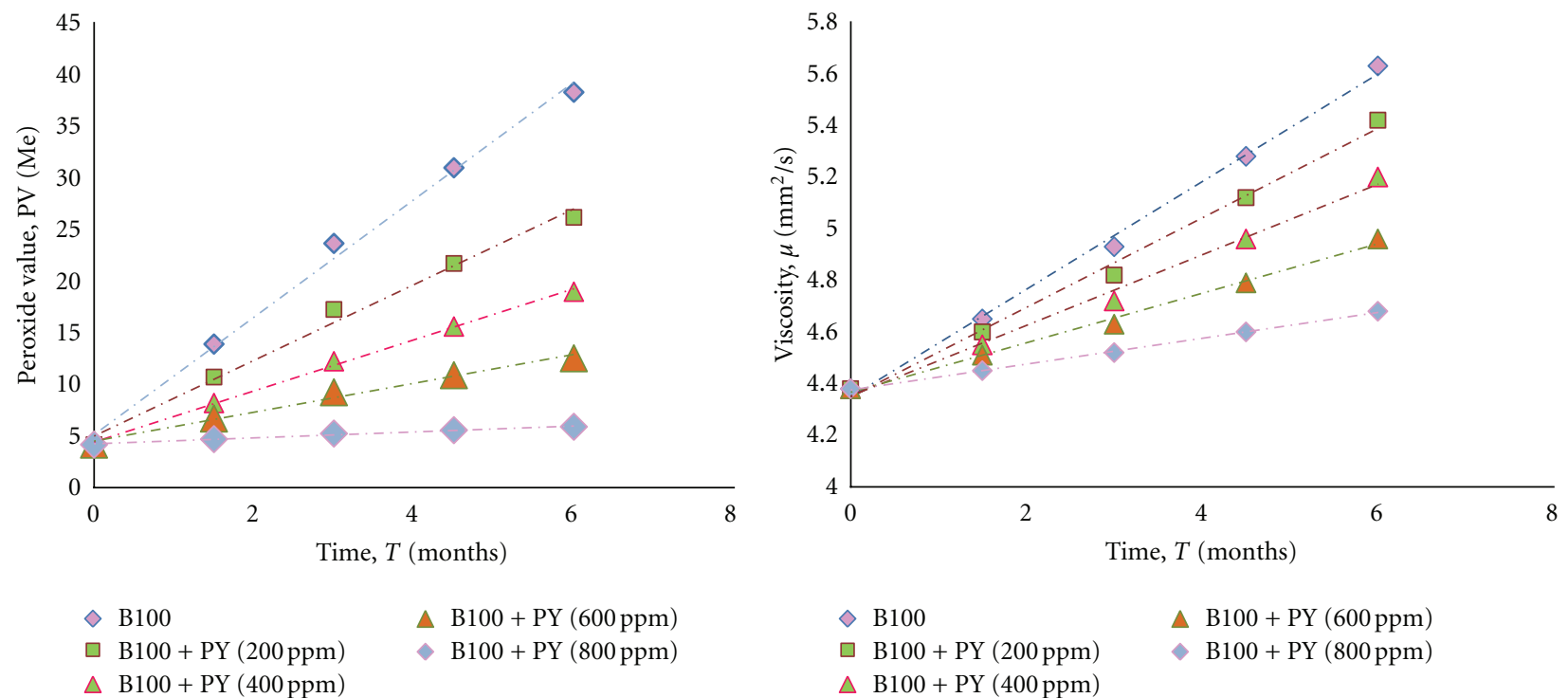

(a)

(b)
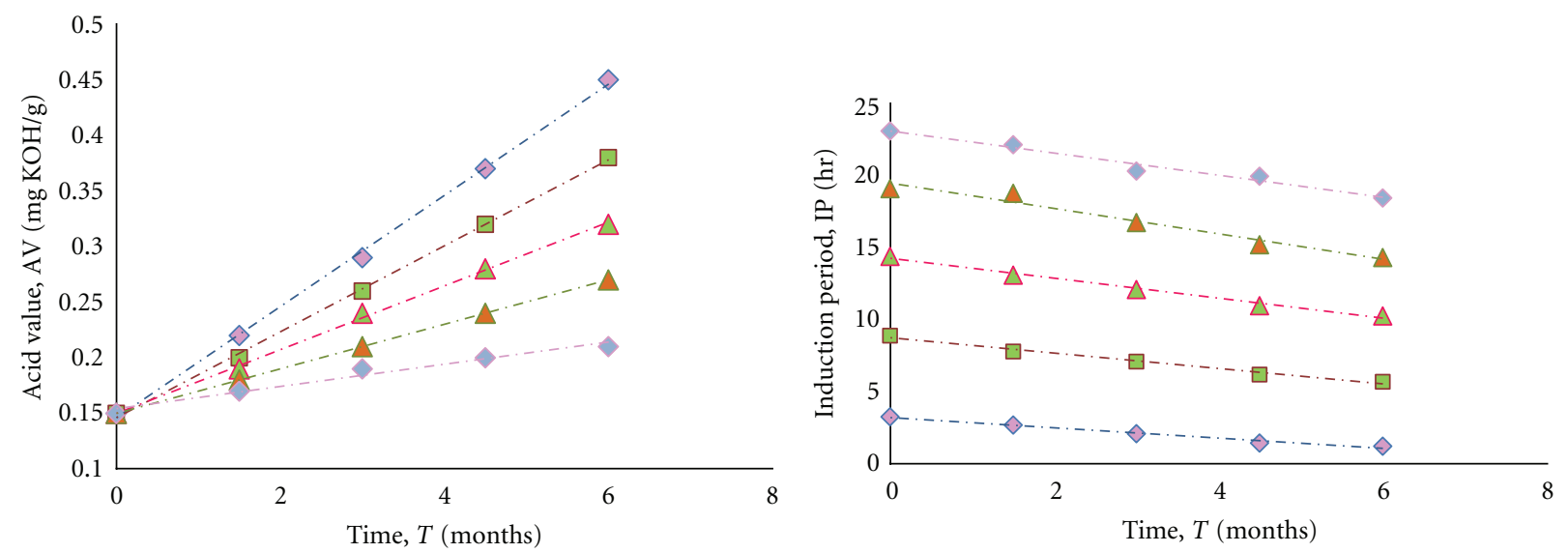

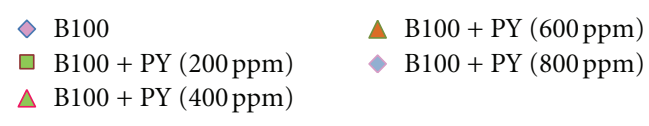

(c)

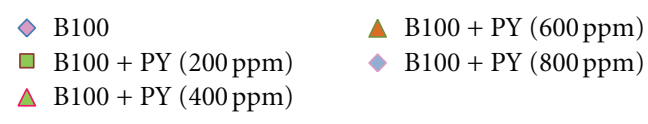

(d)

FIgURE 5: Effect of antioxidant on storage stability of JCB.

Table 10: Predicted models for IP, Ins, and $E_{a}$.

\begin{tabular}{lcl}
\hline S. no. & Metal & Predicted model \\
\hline 1 & $\mathrm{Fe}$ & $\mathrm{IP}=3.52+0.030528 * A-1.84833 * M-5.66667 * 10^{-3} * A * M-7.19444 * 10^{-6} * A^{2}+0.16750 * M^{2}$ \\
2 & $\mathrm{Ni}$ & $\mathrm{IP}=4.05394+0.028184 * A-3.09152 * M-6.33333 * 10^{-3} * A * M C-4.73232 * 10^{-6} * A^{2}+0.78409 * M^{2}$ \\
3 & $\mathrm{Mn}$ & $\mathrm{IP}=4.41515+0.025763 * A-4.36455 * M-6.33333 * 10^{-3} * A * M-7.52525 * 10^{-7} * A^{2}+1.34227 * M^{2}$ \\
4 & $\mathrm{Co}$ & $\mathrm{IP}=4.12273+0.026438 * A-4.34848 * M-8.0 * 10^{-3} * A * M+2.32323 * 10^{-7} * A^{2}+1.40091 * M^{2}$ \\
5 & $\mathrm{Cu}$ & $\mathrm{IP}=3.70909+0.029541 * A-3.82439 * M-8.66667 * 10^{-3} * A * M-5.17929 * 10^{-6} * A^{2}+0.95886 * M^{2}$ \\
\hline
\end{tabular}

IP. This figure shows that the IP improves with increase of antioxidant concentration at constant amount of metal contaminants.

In the same manner, the response analysis of other metalcontaminated biodiesel is conducted. The model developed for IP for all the metals selected for experiment is given in
Table 10. Table 11 is showing the summery of ANOVA for all the metal-contaminated biodiesel.

For all the models, $F$ value is large enough to make the model significant. There is only a $0.01 \%$ chance that a "Model $F$ Value" this large could occur due to noise. In all cases $A$, $M, A M, A^{2}$, and $M^{2}$ are significant model terms. Also lack of 

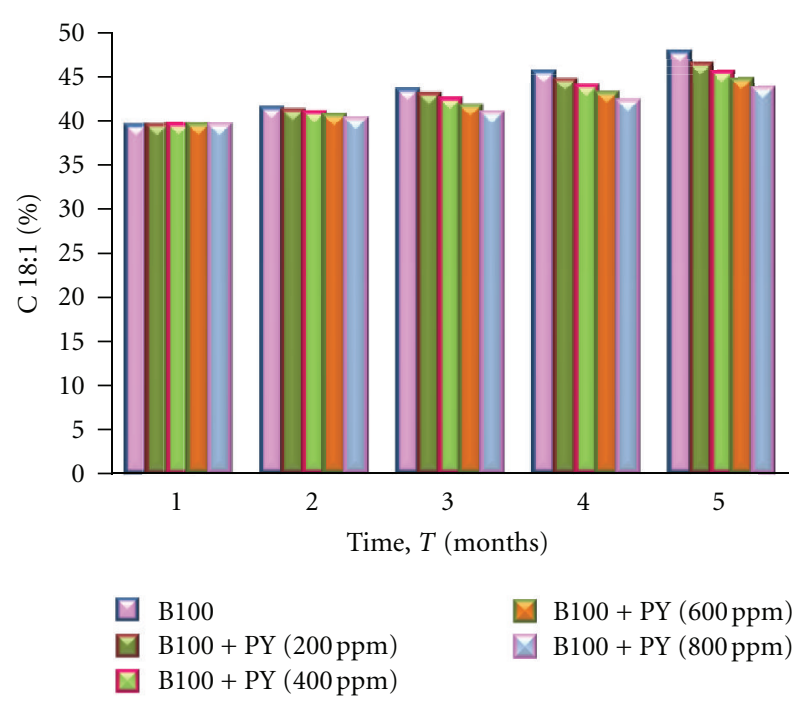

(a)

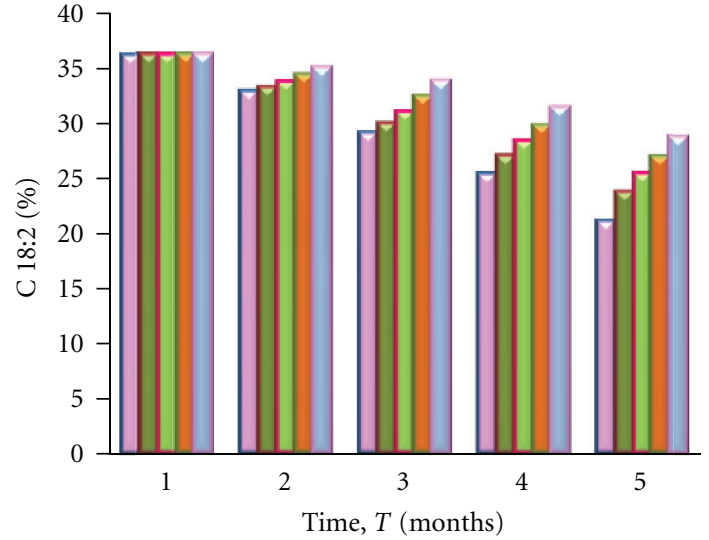

B100

$\square \mathrm{B} 100+\mathrm{PY}(200 \mathrm{ppm})$

$\square \mathrm{B} 100+\mathrm{PY}(400 \mathrm{ppm})$

(b)

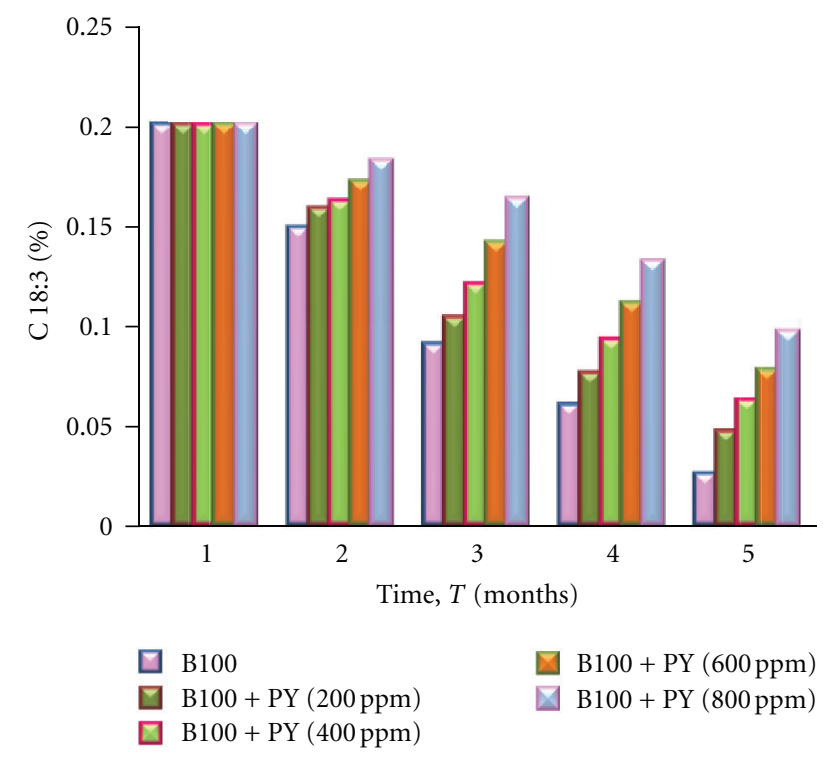

(c)

FIGURE 6: Effect of antioxidant concentration on unsaturated fatty acids with respect to time.

TABLE 11: Summary of ANOVA.

\begin{tabular}{lcccc}
\hline S. no. & $\begin{array}{c}\text { Metal in biodiesel } \\
\text { sample }\end{array}$ & $\begin{array}{c}\text { Model } F \\
\text { value }\end{array}$ & Adjusted $R^{2}$ & Predicted $R^{2}$ \\
\hline 1 & $\mathrm{Fe}$ & 765.75 & 0.9948 & 0.9914 \\
2 & $\mathrm{Ni}$ & 952.28 & 0.9958 & 0.9928 \\
3 & $\mathrm{Mn}$ & 746.96 & 0.9947 & 0.9915 \\
4 & $\mathrm{Co}$ & 872 & 0.9954 & 0.9923 \\
5 & $\mathrm{Cu}$ & 902.34 & 0.9956 & 0.9926 \\
\hline
\end{tabular}

fit is not significant which is desirable. Predicted $R^{2}$ value is in reasonable agreement with adjusted $R^{2}$ value.

Table 12 shows the optimum results for oxidation stability after doping the JCB with metal contaminants (2 ppm) with antioxidant to get an IP of 6 hrs.
TABLE 12: Optimum amount of antioxidant for $6 \mathrm{hr}$ IP.

\begin{tabular}{lccc}
\hline S. no. & Metal & IP $(\mathrm{hr})$ & Antioxidant concentration $(\mathrm{ppm})$ \\
\hline 1 & $\mathrm{Fe}$ & 6 & 326.96 \\
2 & $\mathrm{Ni}$ & 6 & 361.64 \\
3 & $\mathrm{Mn}$ & 6 & 386.15 \\
4 & $\mathrm{Co}$ & 6 & 471.24 \\
5 & $\mathrm{Cu}$ & 6 & 600 \\
\hline
\end{tabular}

The amount of antioxidant shown in Table 12 is the maximum amount to stabilize the JCB because if the metal concentration is increased beyond $2 \mathrm{ppm}$, there will not be any change in the oxidation stability of JCB $[7,17]$. 


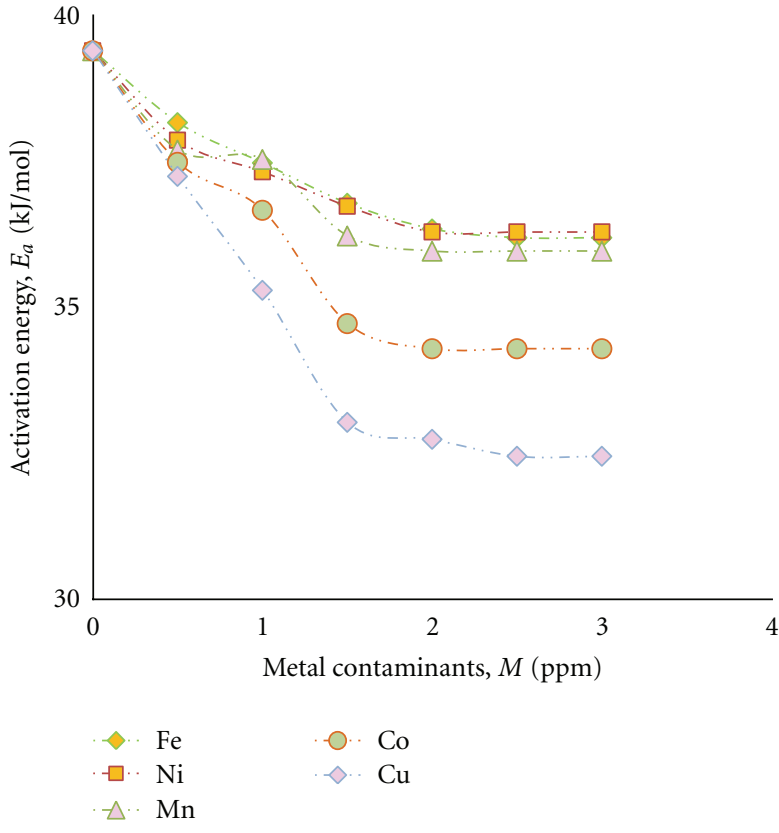

(a)

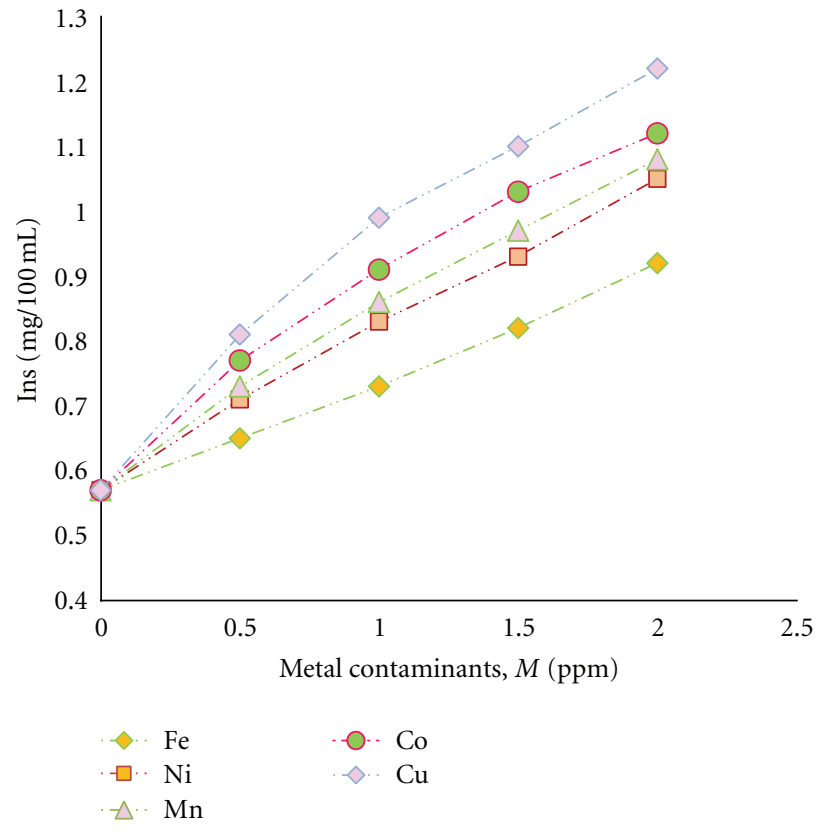

(b)

Figure 7: Effect of metal contamination on thermal stability of JCB.

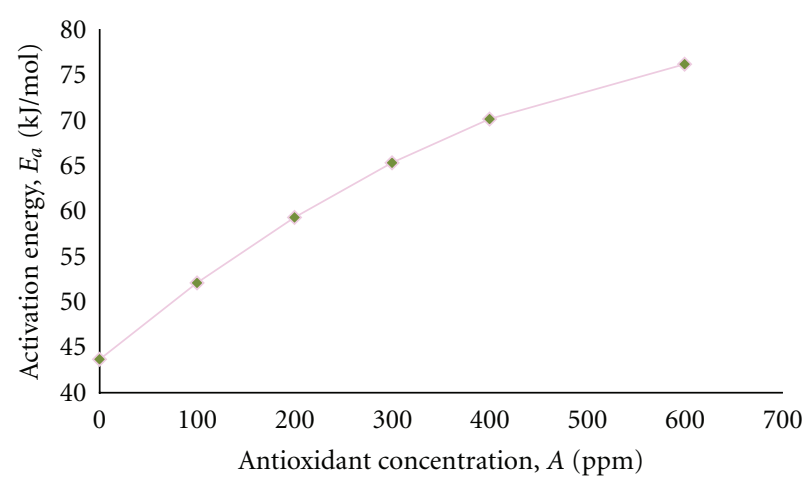

(a)

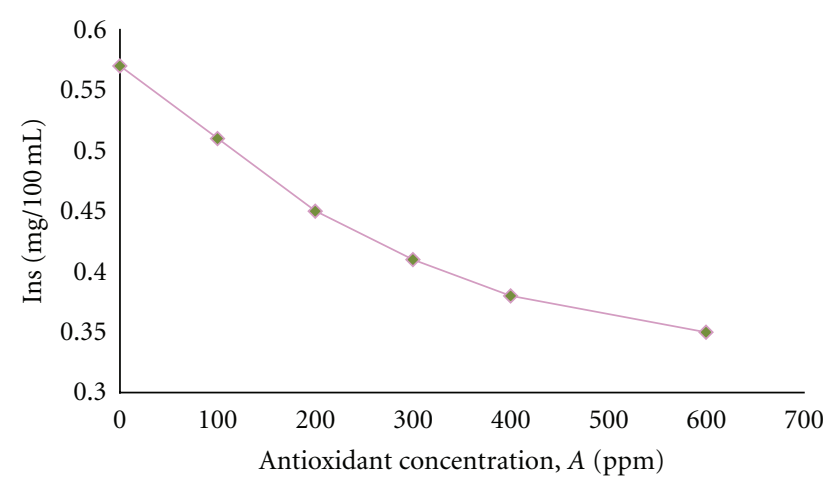

(b)

FIGURE 8: Effect of antioxidants on thermal stability of JCB.

\subsection{Optimization of Thermal Stability}

5.2.1. Response Analysis of Fe Contaminated Biodiesel. The application of RSM yields the following regression equations which are empirical relationship for thermal and oxidation stability in terms of antioxidant concentration and metal concentration:

$$
\begin{aligned}
\text { Ins }= & 0.57091-7.13131 * 10^{-4} * A+0.16273 \\
& * M-2.33333 * 10^{-4} * A * M+5.68182 \\
& * 10^{-7} * A^{2}+6.13636 * 10^{-3} * M^{2}, \\
E_{a}= & 43.67848+0.090157 * A-10.73288 * M+5.23333 \\
& * 10^{-3} * A * M-5.99192 * 10^{-5} * A^{2}-0.42273 \\
& * M^{2} .
\end{aligned}
$$

Common statistical tools in the analysis of variance table such as $F$ value and $P$ value are used to define the most important factors affecting the grape seed proanthocyanidins yields. The $F$ value is defined as the ratio of the respective mean square effect and the mean square error. The $P$ value is defined as the smallest level of significance leading to rejection of the null hypothesis. It may be noted that the standard level of significance used to justify a claim of a statistically significant effect is 0.05 .

Figures 11 and 12 depict contour and response surface plots represented by (3) for thermal stability in terms of Ins. Similarly, this figure reveals that the Ins decreases with increase in antioxidant concentration at constant amount of metal contaminants.

Equation (4) is plotted in Figures 13 and 14 as contour and response surface plots for thermal stability in terms 


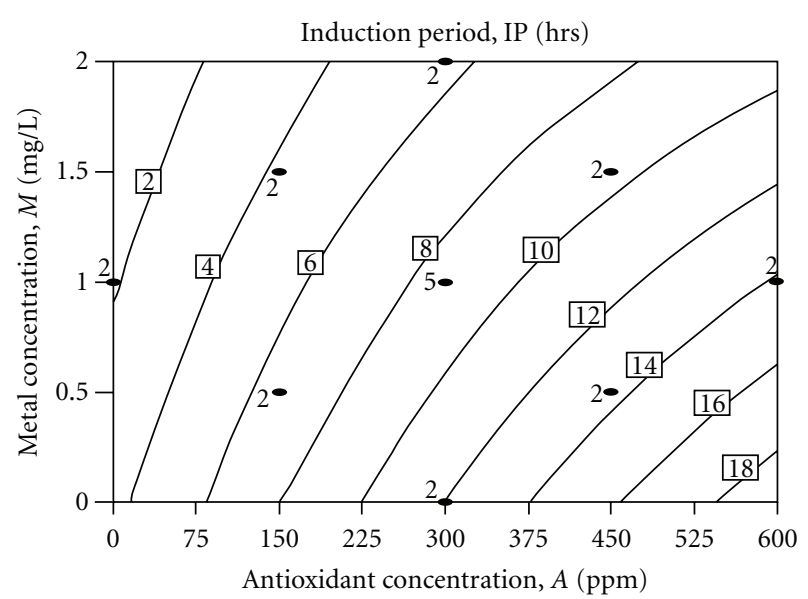

Figure 9: Contour plot of the IP response for JCB.

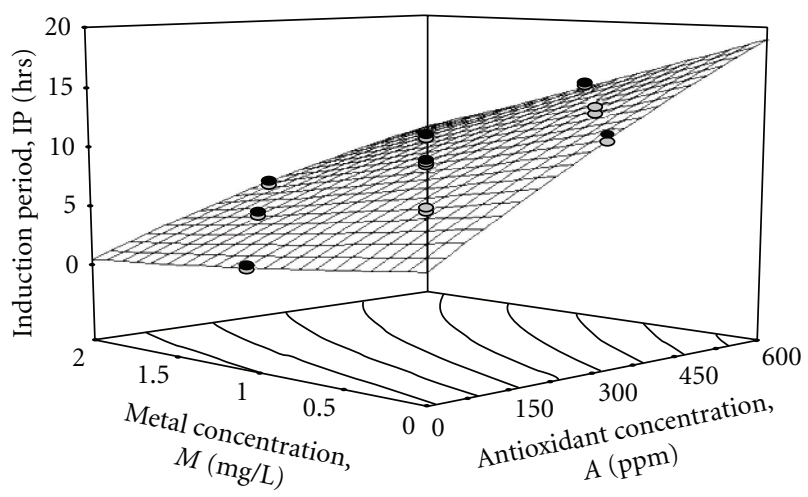

FIgURE 10: The response surface plot of the IP for JCB.

of $E_{a}$. This figure clearly confirms that the $E_{a}$ increases with the increase in amount of antioxidant concentration at constant metal concentration.

In the same manner, the response analysis of other metalcontaminated biodiesel is conducted. The model developed for Ins and $E_{a}$ for all the metals selected for experiment is given in Table 13. Table 14 is showing the summery of ANOVA for all the metal-contaminated biodiesel.

For all the models, $F$ value is large enough to make the model significant. There is only a $0.01 \%$ chance that a "Model $F$ Value" this large could occur due to noise. In all cases $A, M, A M, A^{2}$, and $M^{2}$ are significant model terms. Also lack of fit is not significant which is desirable. Predicted $R^{2}$ value is in reasonable agreement with adjusted $R^{2}$ value.

\subsection{Optimization of Storage Stability}

5.3.1. Response Analysis of Fe-Contaminated Biodiesel. Common statistical tools in the analysis of variance table such as $F$ value and $P$ value are used to define the most important factors affecting the grape seed proanthocyanidins yields. The $F$ value is defined as the ratio of the respective mean square effect and the mean square error. The $P$ value is defined as the smallest level of significance leading to rejection of the null hypothesis. It may be noted that the standard

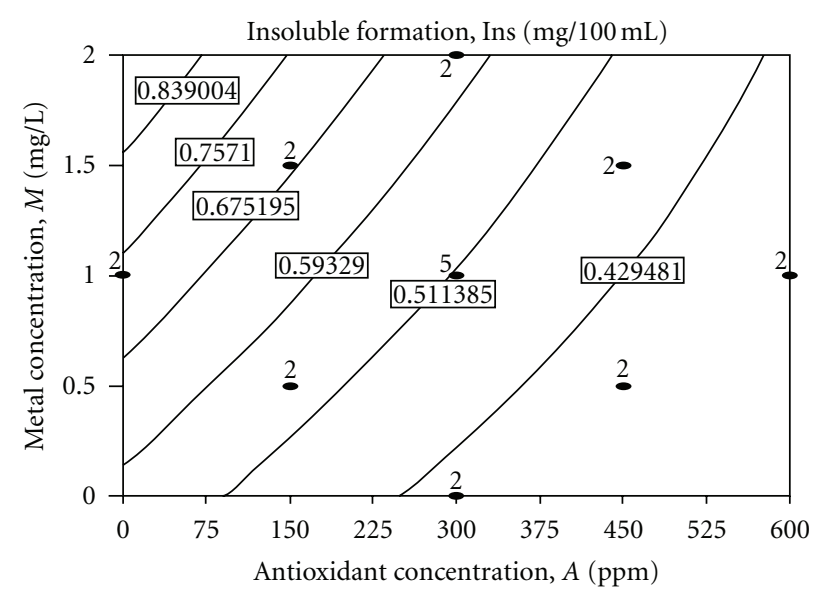

FIgURE 11: Contour plot of the Ins response for JCB.

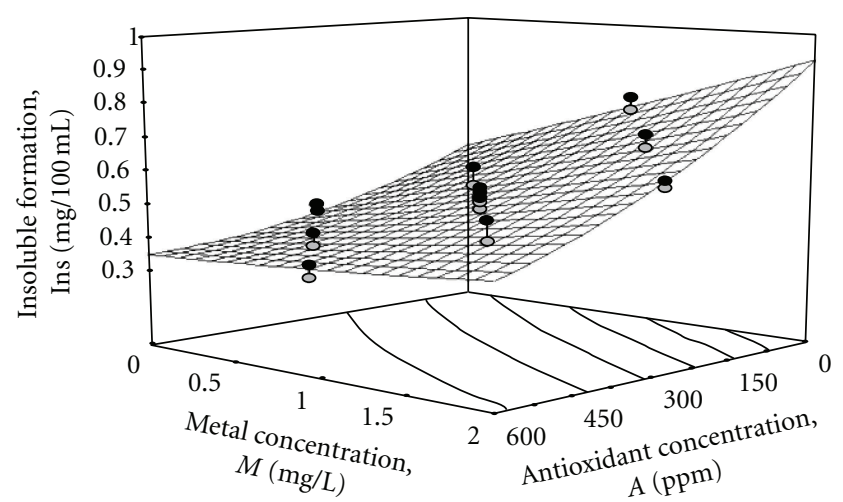

Figure 12: The response surface plot of the Ins for JCB.

level of significance used to justify a claim of a statistically significant effect is 0.05 .

Figure 15 shows the variation of IP with respect to AOC and time while the metal concentration is $0 \mathrm{ppm}$. The figure also shows that if metal concentration is 0 , then $200 \mathrm{ppm}$ PY is sufficient to make biodiesel stable for 6 months. Figure 16 is showing the variation of IP with respect to AOC and time while the metal $(\mathrm{Fe})$ concentration is $2 \mathrm{ppm}$. The figure shows that if metal $(\mathrm{Fe})$ concentration is $2 \mathrm{ppm}$ or more, then $800 \mathrm{ppm}$ PY is sufficient to make biodiesel stable for 5.5 months.

By using RSM, the experimental values of IP are fitted to the statistically significant factors. The second-order model is utilized to develop IP contour and response surface. Using the coefficients determined, the predicted model for Fe-contaminated biodiesel in terms of uncoded (actual) factors for IP is given by

$$
\begin{aligned}
\mathrm{IP}= & 3.74114-0.68440 * T+0.027098 * A-0.68071 \\
& * M-6.87500 E-004 * T * A-0.11000 * T \\
& * M-6.637508 * 10^{-3} * A * M+0.044553 \\
& * T^{2}-9.78261 * 10^{-7} * A^{2}-0.094022 * M^{2} .
\end{aligned}
$$




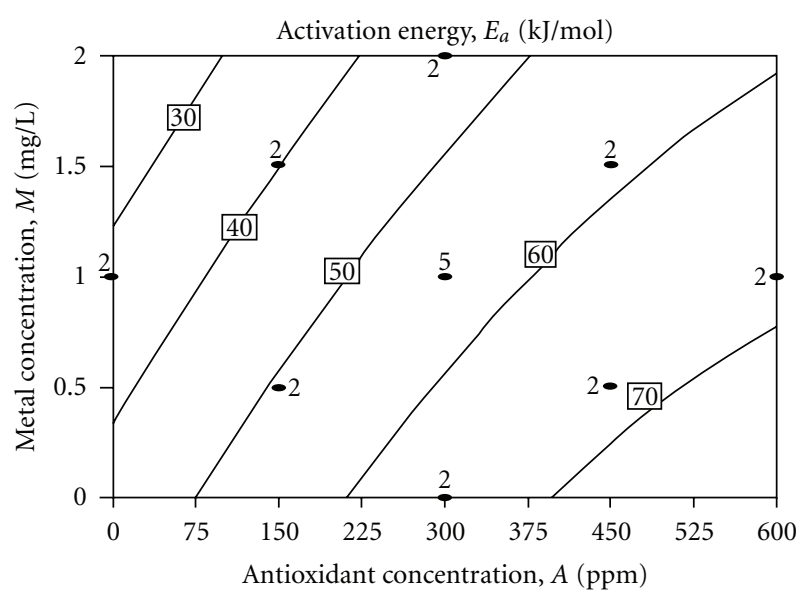

FIGURE 13: Contour plot of the $E_{a}$ response for JCB.

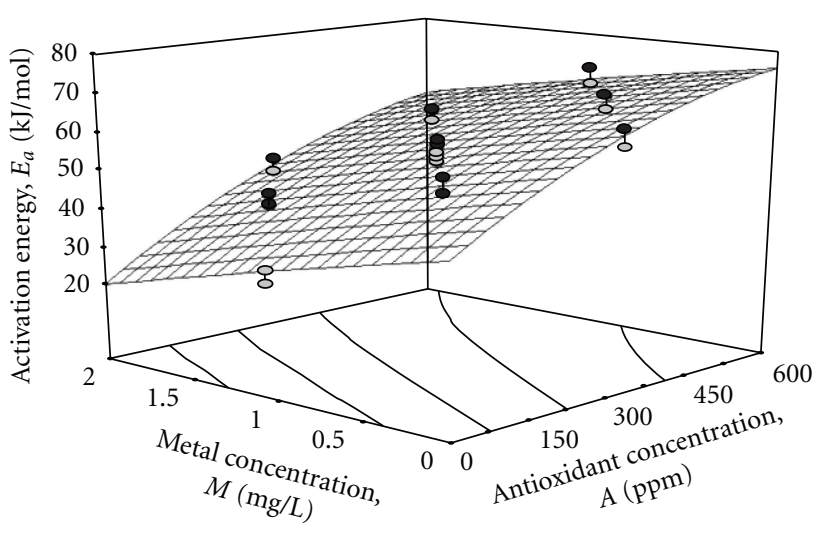

FIgUre 14: The response surface plot of the $E_{a}$ for JCB.

In the same manner, the response analysis of other metalcontaminated biodiesel is conducted. Table 15 gives the summery of ANOVA for all the metal-contaminated biodiesel.

For all the models, $F$ value is large enough to make the model significant. There is only a $0.01 \%$ chance that a "Model $F$ Value" this large could occur due to noise. In all cases $T, A, M, T A, A M$, and $T^{2}$ are significant model terms. Also lack of fit is not significant which is desirable. Predicted $R^{2}$ value is in reasonable agreement with adjusted $R^{2}$ value.

From the previous RSM optimization technique, the maximum time is predicted for which metal-contaminated JCB is stabilized with PY as synthetic antioxidant. According to this if $800 \mathrm{ppm}$ PY is added in Ni contaminated JCB, then the biodiesel can be stabilized for 3.62 months. The same for $\mathrm{Mn}, \mathrm{Co}$, and $\mathrm{Cu}$ is 3.24, 2.76, and 2.07 months, respectively. It is clear from the previous discussion that the presence of these metals reduces the oxidation stability of biodiesel as measured by the IP and this behavior may be attributed due to the acceleration of free radical oxidation due to a metalmediated initiation reaction $[7,16] . \mathrm{Cu}$ is found to have strongest catalytic effect followed by $\mathrm{Co}, \mathrm{Mn}, \mathrm{Ni}$, and Fe. Due to this reason, the antioxidant required for stabilizing the $\mathrm{Cu}$ contaminated biodiesel is also more while the PY required for Fe-contaminated JCB is less than that required in any other

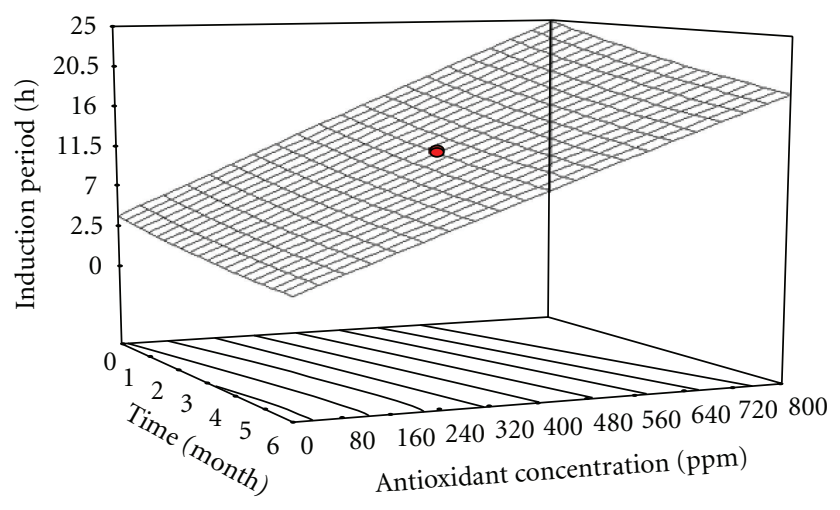

FIGURE 15: Variation in IP with respect to AOC and time while the metal $(\mathrm{Fe})$ concentration is $0 \mathrm{ppm}$.

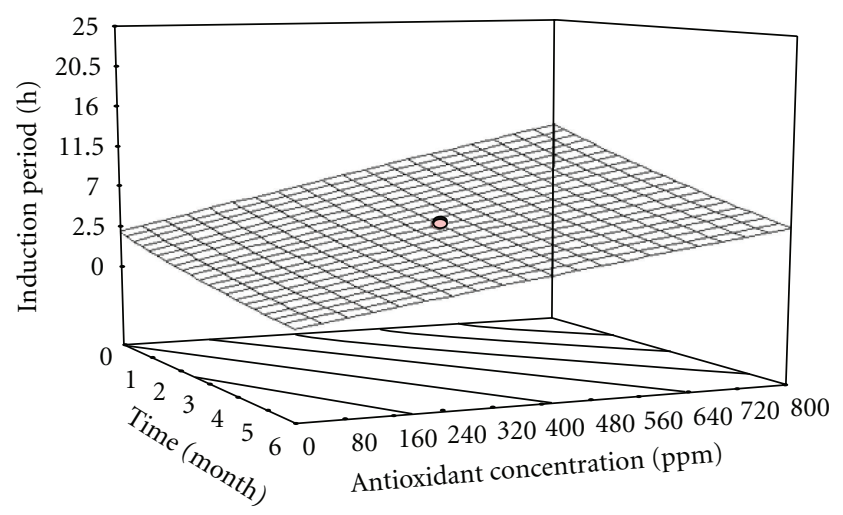

FIGURE 16: Variation in IP with respect to AOC and time while the metal $(\mathrm{Fe})$ concentration is $2 \mathrm{ppm}$.

metal-contaminated JCB. This finding is in agreement with literature [7].

Using the coefficients determined, the predicted model for all metal contaminated biodiesel in terms of uncoded (actual) factors for IP is given in Table 16.

From the previous results, antioxidant concentration can easily be predicted to stabilize the JCB if metal concentration is known. The models developed can be used to predict the amount of antioxidants required to maintain the specification of $6 \mathrm{~h}$ IP for metal contaminated JCB with reasonable accuracy in the range of parameters investigated.

The results indicated that $\mathrm{Cu}$ had strongest catalytic effect followed by $\mathrm{Co}, \mathrm{Mn}, \mathrm{Ni}$, and Fe. Based on the results of various experiments, a number of correlations have also been developed for storage stability in terms of IP as a function of antioxidant concentration, metal concentration, and storage time using RSM. A comparison between the IP obtained from experimental investigation and those predicted by the correlation shows that all the predicted data points lie within $\pm 10 \%$ deviation lines of the experimental results. From the experiments it is found that if metal concentration is 0 , then, $200 \mathrm{ppm}$ PY is sufficient to make biodiesel stable for 6 months. If metal concentration is $2 \mathrm{ppm}$ or more, then 800 ppm PY is sufficient to make biodiesel stable for 
TABLe 13: Predicted models for IP, Ins, and $E_{a}$.

\begin{tabular}{|c|c|c|}
\hline S. no. & Metal & Predicted model \\
\hline 1 & $\mathrm{Fe}$ & $\begin{aligned} \text { Ins }= & 0.57091-7.13131 * 10^{-4} * A+0.16273 * M-2.33333 * 10^{-4} * A \\
& * M+5.68182 * 10^{-7} * A^{2}+6.13636 * 10^{-3} * M^{2} \\
E_{a}= & 43.67848+0.090157 * A-10.73288 * M+5.23333 * 10^{-3} * A \\
& * M-5.99192 * 10^{-5} * A^{2}-0.42273 * M^{2}\end{aligned}$ \\
\hline 2 & $\mathrm{Ni}$ & $\begin{aligned} \text { Ins }= & 0.59788-7.93434 * 10^{-4} * A+0.25197 * M-2.66667 * 10^{-4} * A \\
& * M+6.18687 * 10^{-7} * A^{2}-0.019318 * M^{2} \\
E_{a}= & 46.68424+0.079609 * A-26.89727 * M+0.026567 * A \\
& * M-6.27096 * 10^{-5} * A^{2}+2.60114 * M^{2}\end{aligned}$ \\
\hline 3 & $\mathrm{Mn}$ & $\begin{aligned} \text { Ins }= & 0.60152-8.07071 * 10^{-4} * A+0.28455 * M-3.0 * 10^{-4} * A \\
& * M+6.69192 * 10^{-7} * A^{2}-0.024773 * M^{2} \\
E_{a}= & 45.48939+0.083027 * A-29.82515 * M+0.027333 * A \\
& * M-6.52121 * 10^{-5} * A^{2}+3.33091 * M^{2}\end{aligned}$ \\
\hline 4 & Co & $\begin{aligned} \text { Ins }= & 0.65182-9.98485 * 10^{-4} * A+0.33379 * M-2.66667 * 10^{-4} * A \\
& * M+8.30808 * 10^{-7} * A^{2}-0.040227 * M^{2} \\
E_{a}= & 43.21061+0.089323 * A-36.88318 * M+0.029667 * A \\
& * M-6.90379 * 10^{-5} * A^{2}+5.31159 * M^{2}\end{aligned}$ \\
\hline 5 & $\mathrm{Cu}$ & $\begin{aligned} \text { Ins }= & 0.63394-8.55051 * 10^{-4} * A+0.51015 * M-4.0 * 10^{-4} * A \\
& * M+6.28788 * 10^{-7} * A^{2}-0.098409 * M^{2} \\
E_{a}= & 40.33848+0.097579 * A-45.83288 * M+0.031867 * A \\
& * M-7.48359 * 10^{-5} * A^{2}+8.00977 * M^{2}\end{aligned}$ \\
\hline
\end{tabular}

TABle 14: Summary of ANOVA.

\begin{tabular}{|c|c|c|c|c|c|c|c|}
\hline \multirow{2}{*}{ S. no. } & \multirow{2}{*}{ Metal in biodiesel sample } & \multicolumn{2}{|c|}{ Model $F$ value } & \multicolumn{2}{|c|}{ Adjusted $R^{2}$} & \multicolumn{2}{|c|}{ Predicted $R^{2}$} \\
\hline & & Ins & $E_{a}$ & Ins & $E_{a}$ & Ins & $E_{a}$ \\
\hline 1 & $\mathrm{Fe}$ & 71.76 & 69.31 & 0.9465 & 0.9447 & 0.9213 & 0.9120 \\
\hline 2 & $\mathrm{Ni}$ & 171.11 & 142.41 & 0.9770 & 0.9725 & 0.9627 & 0.9539 \\
\hline 3 & $\mathrm{Mn}$ & 212.87 & 169.80 & 0.9815 & 0.9769 & 0.9707 & 0.9622 \\
\hline 4 & Co & 171.49 & 186.59 & 0.9771 & 0.9789 & 0.9642 & 0.9667 \\
\hline 5 & $\mathrm{Cu}$ & 104.87 & 171.38 & 0.9629 & 0.9771 & 0.9335 & 0.9660 \\
\hline
\end{tabular}

TABLE 15: Summary of ANOVA.

\begin{tabular}{|c|c|c|c|c|c|}
\hline S. no. & Metal in biodiesel sample & Model $F$ value & Lack of fit & Adjusted $R^{2}$ & Predicted $R^{2}$ \\
\hline 1 & $\mathrm{Fe}$ & 760.47 & Not significant & 0.9952 & 0.9933 \\
\hline 2 & $\mathrm{Ni}$ & 1835.65 & Not significant & 0.9980 & 0.9972 \\
\hline 3 & $\mathrm{Mn}$ & 787.06 & Not significant & 0.9954 & 0.9930 \\
\hline 4 & Co & 2328.42 & Not significant & 0.9984 & 0.9978 \\
\hline 5 & $\mathrm{Cu}$ & 1312.02 & Not significant & 0.9972 & 0.9965 \\
\hline
\end{tabular}

TABLE 16: Predicted models for all metal-contaminated biodiesels in terms of uncoded factors.

\begin{tabular}{|c|c|c|}
\hline S. no. & Metal & Predicted model \\
\hline 1 & $\mathrm{Fe}$ & $\begin{aligned} \mathrm{IP}= & 3.74114-0.68440 * T+0.027098 * A-0.68071 * M-6.87500 E-004 * T * A-0.11000 * T \\
& * M-6.637508 * 10^{-3} * A * M+0.044553 * T^{2}-9.78261 * 10^{-7} * A^{2}-0.094022 * M^{2}\end{aligned}$ \\
\hline 2 & $\mathrm{Ni}$ & $\begin{aligned} \mathrm{IP}= & 3.29033-0.20054 * T+0.027068 * A-1.57538 * M-1.17917 * 10^{-3} * T * A-0.076667 * T \\
& * M-7.11250 * 10^{-3} * A * M-9.21498 * 10^{-3} * T^{2}-7.05842 * 10^{-7} * A^{2}+0.21457 * M^{2}\end{aligned}$ \\
\hline 3 & $\mathrm{Mn}$ & $\begin{aligned} \mathrm{IP}= & 3.30432-0.14178 * T+0.027062 * A-2.00035 * M-9.14583 * 10^{-4} * T * A-0.12083 * T \\
& * M-7.49375 * 10^{-3} * A * M-0.018696 * T^{2}-1.47351 * 10^{-6} * A^{2}+0.44674 * M^{2}\end{aligned}$ \\
\hline 4 & $\mathrm{Co}$ & $\begin{aligned} \mathrm{IP}= & 2.84647+0.048388 * T+0.027882 * A-2.02734 * M-1.17500 * 10^{-3} * T * A-1.66667 * 10^{-3} * T \\
& * M-8.08750 * 10^{-3} * A * M-0.044940 * T^{2}-1.12160 * 10^{-6} * A^{2}+0.34304 * M^{2}\end{aligned}$ \\
\hline 5 & $\mathrm{Cu}$ & $\begin{aligned} \mathrm{IP}= & 4.44796-0.64410 * T+0.025363 * A-3.46106 * M-1.14792 * 10^{-3} * T * A+0.11250 * T \\
& * M-8.78125 * 10^{-3} * A * M+0.055302 * T^{2}+2.04823 * 10^{-6} * A^{2}+0.86272 * M^{2}\end{aligned}$ \\
\hline
\end{tabular}




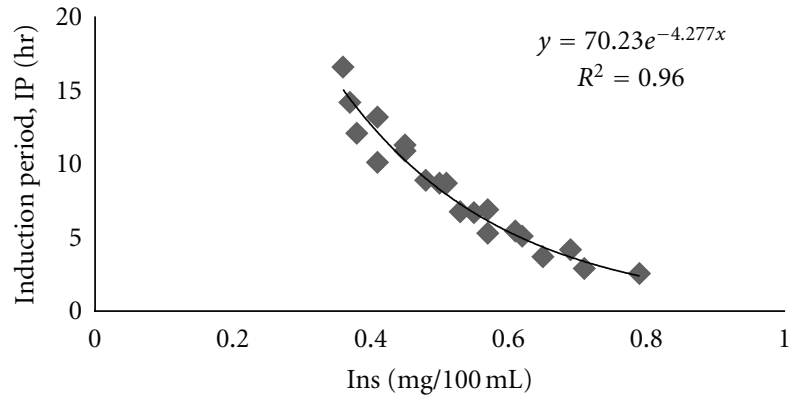

FIGURE 17: Relationship between IP and Ins for Fe-contaminated JCB.

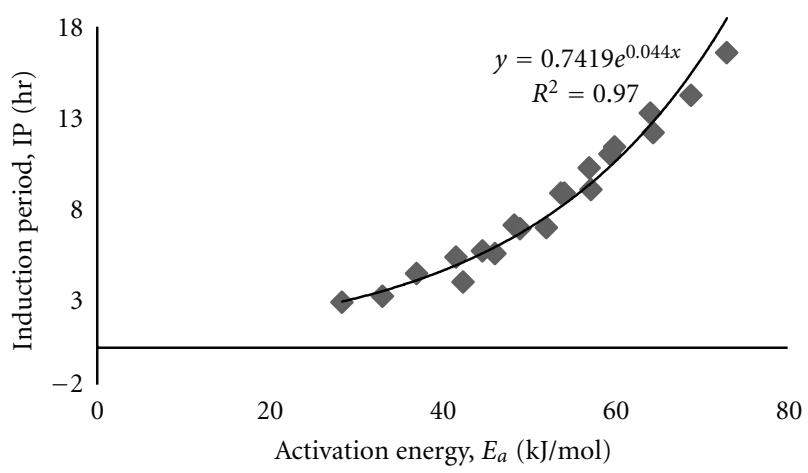

FIGURE 18: Relationship between IP and $E_{a}$ for Fe-contaminated JCB.

TABLE 17: Relationship between oxidation and thermal stability for different metal-contaminated JCB.

\begin{tabular}{lcc}
\hline Metal & Correlation & Correlation coefficient $\left(R^{2}\right)$ \\
\hline \multirow{2}{*}{$\mathrm{Fe}$} & $\mathrm{IP}=70.23 * e^{-4.277 * \text { Ins }}$ & 0.96 \\
& $\mathrm{IP}=0.7419 * e^{0.044 * E_{a}}$ & 0.97 \\
\hline \multirow{2}{*}{$\mathrm{Ni}$} & $\mathrm{IP}=55.837 * e^{-3.606 * \text { Ins }}$ & 0.96 \\
& $\mathrm{IP}=1.2654 * e^{0.036 * E_{a}}$ & 0.96 \\
\hline \multirow{2}{*}{$\mathrm{Mn}$} & $\mathrm{IP}=55.144 * e^{-3.559 * \text { Ins }}$ & 0.94 \\
& $\mathrm{IP}=1.3048 * e^{0.0358 * E_{a}}$ & 0.95 \\
\hline \multirow{2}{*}{$\mathrm{Co}$} & $\mathrm{IP}=60.419 * e^{-3.504 * \text { Ins }}$ & 0.96 \\
& $\mathrm{IP}=1.5279 * e^{0.0342 * E_{a}}$ & 0.94 \\
\hline \multirow{2}{*}{$\mathrm{Cu}$} & $\mathrm{IP}=58.189 * e^{-3.318 * \text { Ins }}$ & 0.87 \\
& $\mathrm{IP}=1.5799 * e^{0.0361 * E_{a}}$ & 0.92 \\
\hline
\end{tabular}

5.5 months. The value of storage time for $\mathrm{Ni}, \mathrm{Mn}, \mathrm{Co}$, and $\mathrm{Cu}$ is 3.62, 3.24, 2.76, and 2.07 months, respectively, if metal and antioxidant concentration is same in all the cases.

\section{Correlation Development between Oxidation and Thermal Stability}

Based on the previous results, different correlations were developed for IP with Ins and $E_{a}$. Figures 17 and 18 show the relation between the oxidation and thermal stability of Fecontaminated JCB. Figure 17 shows that the relation between IP and Ins is exponential with the value of correlation

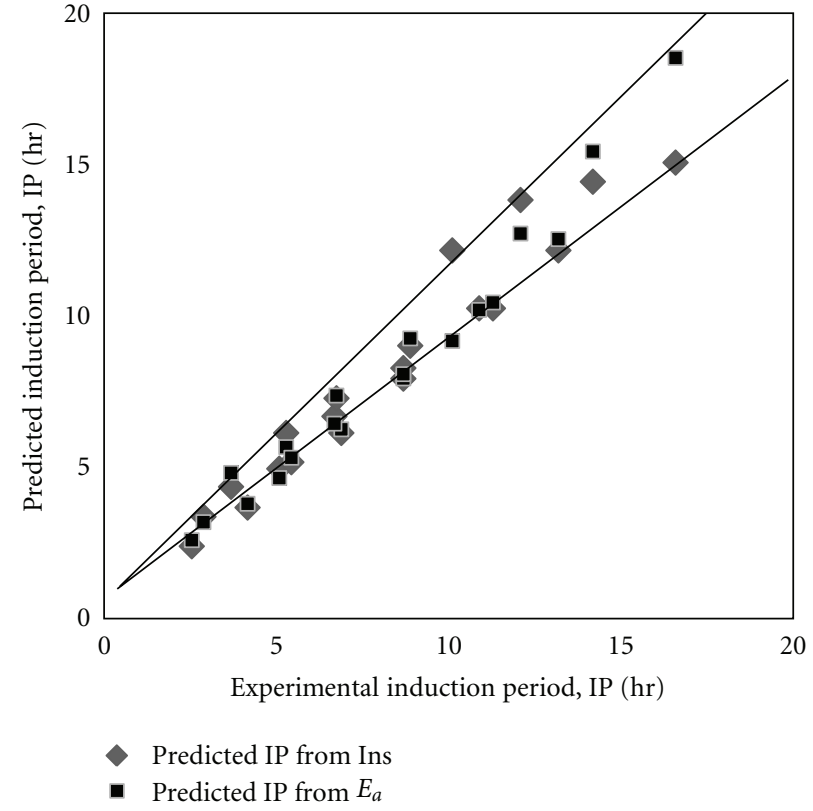

Figure 19: Comparison of experimental and predicted values of IP.

coefficient of 0.96 . Figure 18 is showing that the relation between IP and $E_{a}$ is exponential with the value of correlation coefficient of 0.97 . From both figures it is concluded that with the increase of Ins and decrease in $E_{a}$, IP decreases. Table 17 gives the different correlations for different metal contaminants with the values of regression coefficient.

Figure 19 gives the error between the predicted values and experimental values of IP for Fe-contaminated JCB from which it is clear that the $95 \%$ of the predicted data point lie within $\pm 10 \%$ deviation line of the experimental results.

From the aforementioned part it is concluded that the correlations developed can be used for the prediction of Ins and $E_{a}$ if IP is known or vice versa. As no specification is found, discussing about the maximum limitation of thermal stability, such correlations can be useful to develop the specification for thermal stability of biodiesel.

\section{Conclusions}

In the present paper the various aspects of stability of JCB were studied. For the objective JCB was mixed with PY and different metal contaminants, subjected to open air storage exposed to sunlight condition. Different properties were checked for the measurement of oxidation, thermal, and storage stability of JCB. Based on results of various experiments a number of correlations have also been developed for oxidation stability in terms of IP and for thermal stability in terms of Ins and $E_{a}$ as a function of antioxidant concentration and metal concentration using RSM. Based on the results following conclusions were drawn.

(1) The results indicated that $\mathrm{Cu}$ had strongest catalytic and detrimental effect on the oxidation stability of biodiesel followed by $\mathrm{Co}, \mathrm{Mn}, \mathrm{Ni}$, and $\mathrm{Fe}$. 
(2) A comparison among the IP, Ins, and $E_{a}$ obtained from experimental investigation and those predicted by the correlation shows that all the predicted data points lie within $\pm 10 \%$ deviation lines of the experimental results.

(3) The optimum amount of PY for $2 \mathrm{mg} / \mathrm{L}$ metal contaminated biodiesel to get an IP of $6 \mathrm{hr}$ is computed as 326.96, 361.64, 386.15, 417.24, and 600 ppm for Fe, $\mathrm{Ni}, \mathrm{Mn}, \mathrm{Co}$, and $\mathrm{Cu}$, respectively. This is the maximum amount of PY needed to have an IP of $6 \mathrm{hrs}$ for metal contaminated JCB because beyond $2 \mathrm{mg} / \mathrm{L}$ metal effect on oxidation stability is constant.

(4) It was found that stability of fresh JCB was not acceptable as per EN 14112. Fresh JCB without any metal contaminant was also unstable, and when metal contaminants were mixed with JCB, then its instability is further enhanced and therefore it is not possible to store JCB with and without metal contaminants without the addition of antioxidants.

(5) When PY was mixed with JCB, its stability increased and $200 \mathrm{ppm}$ of PY was sufficient to make fresh and pure JCB stable for almost 6 months.

(6) Unsaturated fatty acid composition was also checked with respect to time. From the experiment it was clear that as oxidation deterioration advances with respect to time, linoleic and linolenic acid methyl esters decrease and the fraction of oleic acid methyl becomes relatively high.

\section{Acknowledgment}

The authors acknowledge the financial support from the Ministry of Human Resource Development (MHRD), Government of India, in the form of a scholarship to carry out this work.

\section{References}

[1] R. O. Dunn, "Effect of temperature on the oil stability index (OSI) of biodiesel," Energy and Fuels, vol. 22, no. 1, pp. 657$662,2008$.

[2] S. Jain and M. P. Sharma, "Prospects of biodiesel from Jatropha in India: a review," Renewable and Sustainable Energy Reviews, vol. 14, no. 2, pp. 763-771, 2010.

[3] M. Mittelbach and S. Schober, "The influence of antioxidants on the oxidation stability of biodiesel," JAOCS, Journal of the American Oil Chemists' Society, vol. 80, no. 8, pp. 817-823, 2003.

[4] R. O. Dunn, "Effect of antioxidants on the oxidative stability of methyl soyate (biodiesel)," Fuel Processing Technology, vol. 86, no. 10, pp. 1071-1085, 2005.

[5] R. Sarin, M. Sharma, S. Sinharay, and R. K. Malhotra, "Jatropha-Palm biodiesel blends: an optimum mix for Asia," Fuel, vol. 86, no. 10-11, pp. 1365-1371, 2007.

[6] Y. C. Liang, C. Y. May, C. S. Foon, M. A. Ngan, C. C. Hock, and Y. Basiron, "The effect of natural and synthetic antioxidants on the oxidative stability of palm diesel," Fuel, vol. 85, no. 5-6, pp. 867-870, 2006.
[7] A. Sarin, R. Arora, N. P. Singh, M. Sharma, and R. K. Malhotra, "Influence of metal contaminants on oxidation stability of Jatropha biodiesel," Energy, vol. 34, no. 9, pp. 1-5, 2009.

[8] C. W. Fritsch, V. E. Weiss, and R. H. Anderson, "Effect of antioxidants on refined palm oil," Journal of the American Oil Chemists Society, vol. 52, 1975.

[9] S. Jain and M. P. Sharma, "Non-edible oil resources as alternative source of diesel," in Proceedings of the International Conference on Advances in Renewable Energy (ICARE'10), pp. 717726, National Institute of Technology, Bhopal, India, 2010.

[10] S. Jain and M. P. Sharma, "Kinetics of acid base catalyzed transesterification of Jatropha curcas oil," Bioresource Technology, vol. 101, no. 20, pp. 7701-7706, 2010.

[11] S. Jain and M. P. Sharma, "Biodiesel production from Jatropha curcas oil," Renewable and Sustainable Energy Reviews, vol. 14, no. 9, pp. X3140-3147, 2010.

[12] "Standard Test Method for High Temperature Stability of Middle Distillate Fuels," ASTM standard D, 6468-08.

[13] W. B. Wan Nik, F. N. Ani, and H. H. Masjuki, "Thermal stability evaluation of palm oil as energy transport media," Energy Conversion and Management, vol. 46, no. 13-14, pp. 21982215, 2005.

[14] S. Jain and M. P. Sharma, "Measurement of the oxidation stability of biodiesel using a modified Karl Fischer Apparatus," Journal of the American Oil Chemists' Society, vol. 8, pp. 899$905,2010$.

[15] K. Yamane, K. Kawasaki, K. Sone, T. Hara, and T. Prakoso, "Oxidation stability of biodiesel and its effects on diesel combustion and emission characteristics," International Journal of Engine Research, vol. 8, no. 3, pp. 307-319, 2007.

[16] L. M. Das, D. K. Bora, S. Pradhan, M. K. Naik, and S. N. Naik, "Long-term storage stability of biodiesel produced from Karanja oil,” Fuel, vol. 88, no. 11, pp. 2315-2318, 2009.

[17] S. Jain and M. P. Sharma, "Oxidation stability of blends of Jatropha biodiesel with diesel," Fuel, vol. 90, no. 10, pp. 30143020, 2011.

[18] P. Bondioli, A. Gasparoli, L. Della Bella, S. Tagliabue, and G. Toso, "Biodiesel stability under commercial storage conditions over one year," European Journal of Lipid Science and Technology, vol. 105, no. 12, pp. 735-741, 2003.

[19] M. Mittelbach and S. Gangl, "Long storage stability of biodiesel made from rapeseed and used frying oil," Journal of the American Oil Chemists' Society, vol. 78, no. 6, pp. 573-577, 2001.

[20] P. Bondioli, A. Gasparoli, A. Lanzani, E. Fedeli, S. Veronese, and M. Sala, "Storage stability of biodiesel," Journal of the American Oil Chemists' Society, vol. 72, no. 6, pp. 699-702, 1995.

[21] J. C. Thompson, C. L. Peterson, D. L. Reece, and S. M. Beck, "Two-year storage study with methyl and ethyl esters of rapeseed," Transactions of the American Society of Agricultural Engineers, vol. 41, no. 4, pp. 931-939, 1998. 

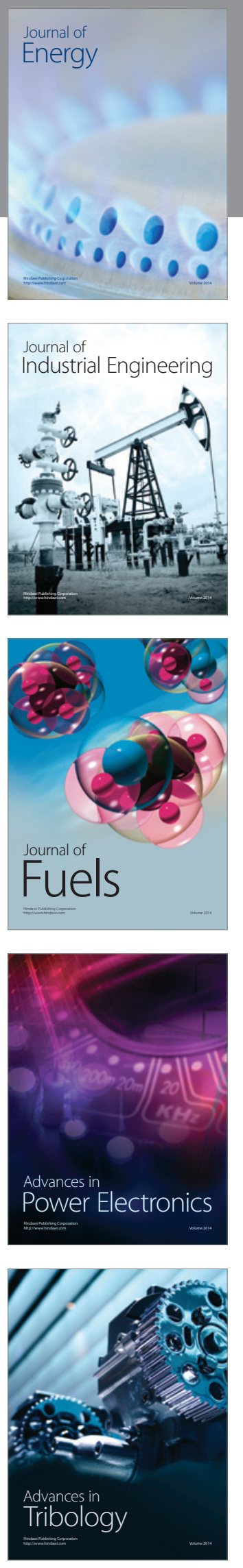
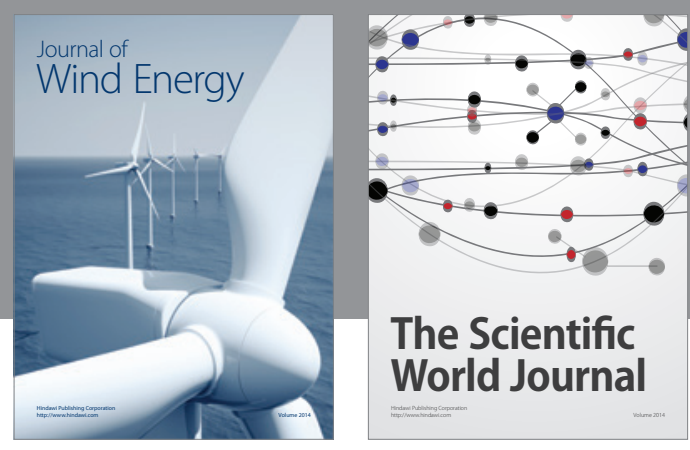

The Scientific World Journal

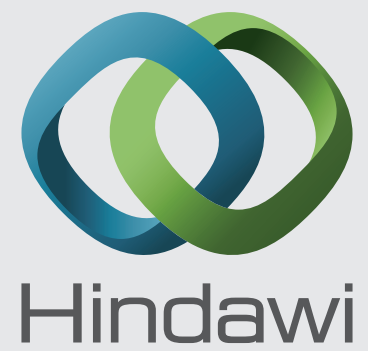

Submit your manuscripts at http://www.hindawi.com
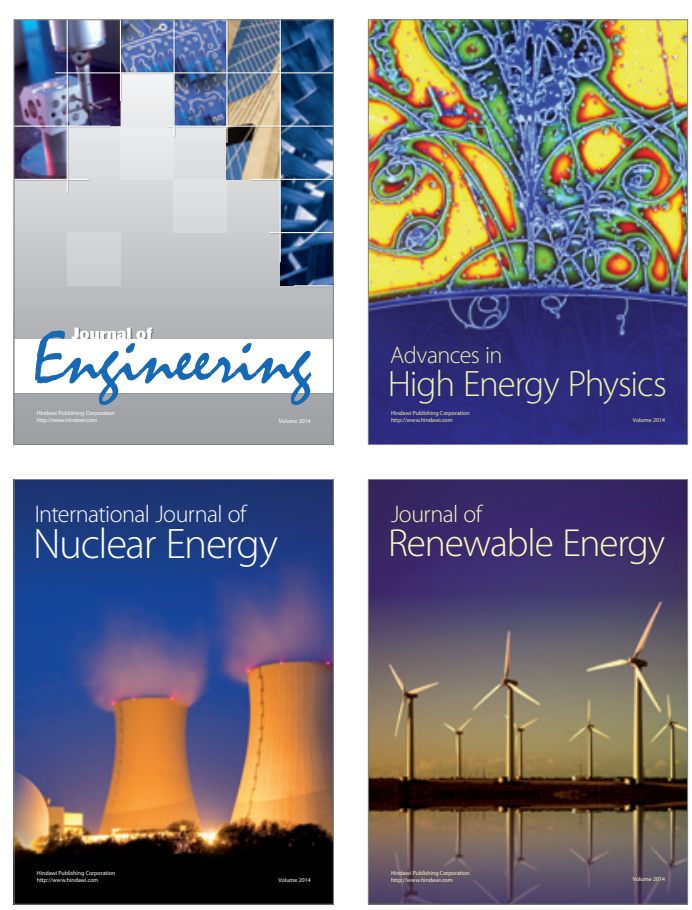

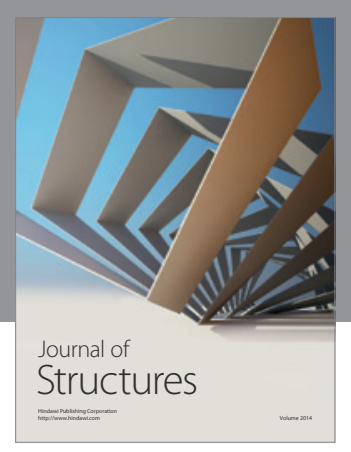

Rotating
Mechinery
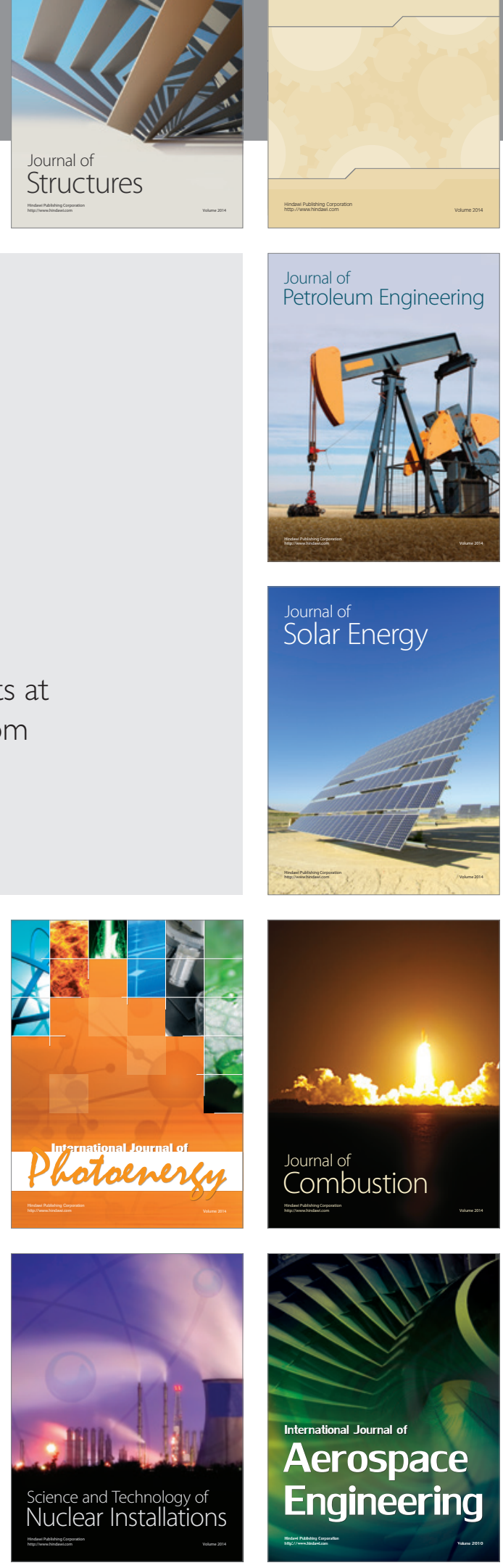